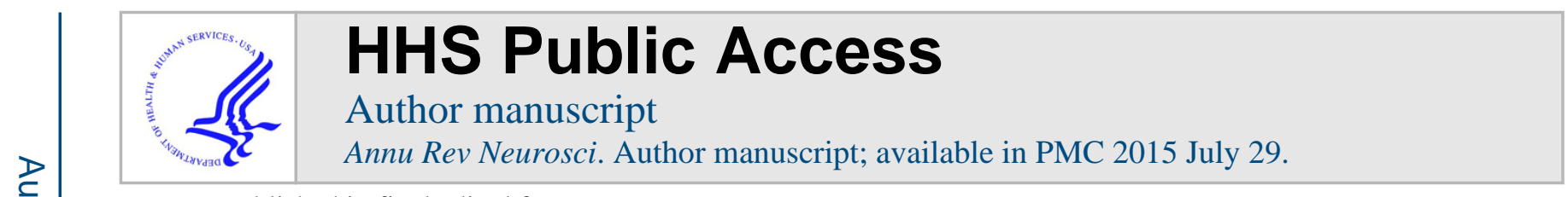

Published in final edited form as:

Апnи Rev Neurosci. 2006 ; 29: 229-257. doi:10.1146/annurev.neuro.29.051605.112824.

\title{
Deep Brain Stimulation
}

\author{
Joel S. Perlmutter ${ }^{1}$ and Jonathan W. Mink ${ }^{2}$ \\ Joel S. Perlmutter: joel@npg.wustl.edu; Jonathan W. Mink: Jonathan_Mink@urmc.rochester.edu \\ ${ }^{1}$ Departments of Neurology, Radiology, Physical Therapy and Anatomy \& Neurobiology, \\ Washington University School of Medicine, Washington University in St. Louis, St. Louis, Missouri \\ 63110 \\ ${ }^{2}$ Departments of Neurology, Neurobiology \& Anatomy, Brain \& Cognitive Sciences, and \\ Pediatrics, University of Rochester, Rochester, New York 14642
}

\begin{abstract}
Deep brain stimulation (DBS) has provided remarkable benefits for people with a variety of neurologic conditions. Stimulation of the ventral intermediate nucleus of the thalamus can dramatically relieve tremor associated with essential tremor or Parkinson disease (PD). Similarly, stimulation of the subthalamic nucleus or the internal segment of the globus pallidus can substantially reduce bradykinesia, rigidity, tremor, and gait difficulties in people with PD. Multiple groups are attempting to extend this mode of treatment to other conditions. Yet, the precise mechanism of action of DBS remains uncertain. Such studies have importance that extends beyond clinical therapeutics. Investigations of the mechanisms of action of DBS have the potential to clarify fundamental issues such as the functional anatomy of selected brain circuits and the relationship between activity in those circuits and behavior. Although we review relevant clinical issues, we emphasize the importance of current and future investigations on these topics.
\end{abstract}

\section{Keywords}

movement disorders; Parkinson disease; dystonia; tremor; physiology

\section{INTRODUCTION}

Deep brain stimulation (DBS) has provided dramatic clinical benefit for people with essential tremor (ET) and Parkinson disease (PD). Placement of high frequency stimulating electrodes in the region of the ventral intermediate nucleus of the thalamus (VIM) can markedly reduce tremor in these conditions, and stimulation of either the subthalamic nucleus (STN) or the internal segment of the globus pallidus (GPi) may not only reduce tremor, but also decrease bradykinesia, rigidity, and gait impairment that plague people with PD. Furthermore, many have touted the potential benefit of DBS of selected brain regions for other movement disorders such as dystonia or Tourette syndrome, as well as a variety of disorders such as pain, depression, and obsessive compulsive disorder (OCD). Despite these realized and potential advances in treatment, controversy swirls around a number of 
clinically relevant and basic mechanistic issues. What conditions are amenable to treatment by DBS? What are the mechanisms of action of DBS? What effect does DBS have on the function of brain circuits? We address these controversial issues and emphasize the need for future investigations. To set the stage, however, we first review the history of the development of DBS as a therapeutic tool.

\section{HISTORY OF DEEP BRAIN STIMULATION}

Ever since Fritsch \& Hitzig's (1870) classical demonstration of the localized electrical excitability of the motor cortex, electrical stimulation of the brain has played a major role in investigations of brain function. The first report of human cortical stimulation appeared four years later (Bartholow 1874). Although electrical stimulation was used to map cortical function in the 1930s (Penfield \& Boldrey 1937), it was not until human stereotaxic devices were developed that neurosurgeons could begin to investigate the effects of stimulating deeper structures (Spiegel et al. 1947). By the early 1950s, intraoperative stimulation was used to identify deep structures such as the corticospinal tract prior to lesioning the globus pallidus or thalamus (Spiegel \& Wycis 1952). Most reports in the 1950s focused on positive phenomena that were elicited by stimulation. In the early 1960s, it was reported that highfrequency $(100-\mathrm{Hz})$ stimulation of the ventrolateral thalamus could diminish tremor (Hassler et al. 1960, Ohye et al. 1964).

The idea of treating neurologic disorders with chronic stimulation began to emerge in the 1960s, but stimulation was largely used for targeting surgical lesions (Bergstrom et al. 1966). Sem-Jacobsen (1966) developed a method of implanting a bundle of multiple electrode wires deep in the brain and leaving them in place for weeks, during which stimulation could be delivered. The goal of the stimulation was to delineate the "best" target for a subsequent lesion. With the implanted wires, a lesion could be made in small steps over a span of days to weeks to try to achieve maximum benefit without untoward effects. Although the goal was still lesion guidance, this is perhaps the earliest report of stimulation through chronically implanted electrodes.

In the early 1970s, reports of using chronic stimulation therapeutically emerged for treating pain (Hosobuchi et al. 1973), movement disorders, or epilepsy (Cooper 1973). Cooper et al. (1976) published the first large series of chronic cerebellar stimulation studies for cerebral palsy. In those cases, stimulation was delivered transcutaneously through inductive coupling devices to electrodes implanted on the surface of the cerebellar cortex. Benefit was said to occur in 49 of 50 patients. However, cerebellar stimulation in cerebral palsy eventually fell out of favor when blinded studies failed to show consistent benefits (Penn 1982). By 1980, other reports of treating movement disorders with chronic stimulation had appeared (Brice \& McLellan 1980).

Although the first long-term internally implanted cardiac pacemaker was developed by 1960 , it was not until the 1990s that implantable pacemaker technology was combined with chronically implanted deep brain electrodes for long-term chronic DBS (Benabid et al. 1991, 1996). Since then, DBS has become increasingly used for treating a variety of disorders.

These are summarized briefly in the section below. 


\section{CLINICAL APPLICATIONS OF DEEP BRAIN STIMULATION}

\section{Deep Brain Stimulation for Essential Tremor}

The first widespread use of DBS in the United States and Europe was for the treatment of ET or the tremor of PD. Benabid and colleagues (1991) first reported the efficacy of VIM stimulation with implantable pulse generators. Subsequently, they reported a larger series of patients with VIM stimulation for the treatment of tremor, with significant benefit in the majority of patients (Benabid et al. 1996). Subsequent single and multicenter studies have consistently reported substantial benefit of VIM stimulation for ET with an average tremor reduction of over 80\% in the majority of patients (Koller et al. 1999a, Ondo et al. 1998, Rehncrona et al. 2003).

\section{Deep Brain Stimulation for Parkinson Disease}

Different sites of stimulation provide different clinical effects in PD. Thalamic stimulation in the region of the VIM may reduce limb tremor (Kumar et al. 2003, Putzke et al. 2003) but has little effect on other manifestations of the disease (Benabid et al. 1996). Stimulation of the GPi may reduce all of the major motor manifestations of PD, including the reduction of dopa-induced dyskinesias, involuntary movements produced by individual doses of dopaminergic medications that can limit treatment efficacy (Anderson et al. 2005, Peppe et al. 2001). GPi stimulation also may reduce painful cramps and sensory symptoms that may occur when the benefit from individual doses of levodopa abates (Loher et al. 2002).

However, GPi stimulation does not typically permit the reduction of medication, and this may be a serious limitation for those having drug-induced side effects such as orthostasis, psychosis, daytime lethargy, or cognitive impairment. STN DBS provides similar reduction of motor symptoms (Benabid et al. 1998; Burchiel et al. 1999; Koller et al. 1999b, 2000b, 2001; Kumar et al. 1998b; Taha et al. 1999). Several studies indicate that bilateral STN DBS improves gait, tremor, and bradykinesia (Bastian et al. 2003; Kumar et al. 1998a, 1999b; Rizzone et al. 2002; Ferrarin et al. 2005) and also permits the reduction of dopaminergic medications leading to fewer drug-induced adverse events (Kumar et al. 1998a, 1998b; Nutt et al. 2001; Pollak et al. 2002; Russmann et al. 2004). Direct, uncontrolled comparisons of GPi DBS with STN DBS have been done (Volkmann et al. 2001), but a preliminary report of a controlled comparison of the benefit from GPi DBS versus STN DBS (Anderson et al. 2005) confirms the comparable clinical benefit from stimulation at either site with little change in preoperative medications in the GPi group as opposed to the STN group.

The degree of benefit from STN DBS or GPi DBS does not usually exceed that found from individual doses of levodopa in each patient (Pahwa et al. 2005), but DBS affords two main advantages: (a) It reduces the time a patient spends in the "off" state when the benefit from an individual dose of medication has diminished-for some this off state leaves a person slow, shaky, stiff, and unable to rise from a chair, and $(b)$ it permits the reduction of medications and their attendant untoward effects (Jaggi et al. 2004). The benefit from surgery appears sustained for at least 4 years (Rodriguez-Oroz et al. 2004, VisserVandewalle et al. 2005) although some complications appear to be cumulative (Lyons et al. 2004). Several studies have demonstrated an improved quality of life from STN DBS (Diamond \& Jankovic 2005, Lyons \& Pahwa 2005). The best candidates for DBS are those 
with a short duration of benefit from individual doses of levodopa, those who have a substantial motor benefit from oral medication, and those who may be limited by dopainduced side effects. Cognitive impairment such as disorientation or memory deficits may be exacerbated by DBS and is a relative contraindication for the procedure.

Interestingly, STN DBS may impair certain aspects of cognitive processing. Stimulation settings optimized for motor benefit may impair spatial delayed recall or response inhibition (Hershey et al. 2004). Others have found STN DBS may improve some executive functions, whereas GPi DBS may produce deleterious effects (Jahanshahi et al. 2000). However, relatively simple cognitive tasks may be unchanged or improved by STN DBS, whereas more difficult demanding tasks could be impaired (Hershey et al. 2004). Socially important activities such as the identification of the emotional tone of an angry face may be impaired (Schroeder et al. 2004). STN DBS also may produce untoward emotional responses, including manic responses (Herzog et al. 2003), hallucinations (Diederich et al. 2000), decreased mood (Berney et al. 2002), and yet at other times may provide an antidepressant effect (Takeshita et al. 2005).

\section{Deep Brain Stimulation for Dystonia}

With the emergence of DBS for treating PD and tremor, there was a natural temptation to try it for dystonia. Stereotaxic ablations of the globus pallidus or thalamus had been used for many years in the treatment of medically refractory generalized dystonia; however, their performance was not widespread. Early reports of DBS for dystonia involved the thalamus (Sellal et al. 1993) and the globus pallidus internal segment (Kumar et al. 1999a). With the increasing success of pallidotomy for generalized dystonia caused by the DYT1 mutation, the globus pallidus became the primary target for primary dystonia, but the thalamic target is still used (Eltahawy et al. 2004, Lozano et al. 1997, Vitek et al. 1998, Yoshor et al. 2001). In a recent controlled trial of pallidal DBS in 22 patients with primary generalized dystonia, there was a 30\%-50\% improvement in symptoms (Vidailhet et al. 2005). Uncontrolled trials have also produced promising results for primary generalized dystonia (Coubes et al. 2004). Smaller series of case reports have suggested potential efficacy for treating primary cervical dystonia (Kiss et al. 2004) and some forms of secondary dystonia (Castelnau et al. 2005).

Although DBS for treating dystonia requires further investigation, early results are promising.

\section{Deep Brain Stimulation for Tourette Syndrome}

There have been a few recent reports of DBS for Tourette Syndrome (Diederich et al. 2005, Temel \& Visser-Vandewalle 2004). The centromedian-parafascicular complex of the thalamus has been targeted bilaterally in the majority of those cases (Houeto et al. 2005, Visser-Vandewalle et al. 2003), but the GPi (Diederich et al. 2005, Houeto et al. 2005) and the anterior limb of the internal capsule (Flaherty et al. 2005) also have been targeted. To date, six cases of DBS for Tourette Syndrome have been published, and there are insufficient data to compare efficacy across targets. However, all patients have had some degree of tic reduction with DBS in these targets. 


\section{Deep Brain Stimulation for Pain}

DBS has been used for more than 50 years to treat a variety of intractable pain syndromes, including neuropathic pain, phantom-limb pain, failed low back pain, and cluster-headache pain. A variety of papers based on anectodal experience or open-label studies suggest DBS provides short- or long-term benefit in a variety of these syndromes (Tasker \& Vilela 1995). The benefit varies depending upon length of follow-up, the condition treated, the definition of adequate pain relief, and the site of stimulation (Bittar et al. 2005). Sites of stimulation have varied from the sensory thalamus to the periaquaductal gray, periventricular gray, posterior hypothalamus (Franzini et al. 2003), internal capsule (Kumar et al. 1997), and the motor cortex (Tirakotai et al. 2005). Some believe that stimulation of the periaquaductal gray or periventricular gray is particularly efficacious for nociceptive pain, whereas DBS of the sensory thalamus is more effective for deafferentation pain (Levy et al. 1987). A study in six patients with cluster headaches suggested that DBS of the ipsilateral ventroposterior hypothalamus reduces cluster headache attacks, but one of the patients died from a perisurgical intracerebral hemorrhage (Schoenen et al. 2005). Clearly the risk is not benign. Higher points of stimulation such as cortical targets may be more likely to reduce pain in poststroke pain syndromes based on open-label reports (Katayama et al. 2001b). Similarly, DBS of the thalamus may reduce pain in phantom-limb syndrome based on open-label evaluation (Katayama et al. 2001a). Interestingly one study used functional magnetic resonance imaging (fMRI) to identify activation in the posterior inferior hypothalamus in people with facial pain associated with short-lasting unilateral neuralgiform headache attacks with conjunctival injection and tearing and then targeted DBS in that area to provide pain relief for those patients (Leone et al. 2005). Mapping evoked responses to painful stimuli may be a way to identify nociceptive cells in the brain that could be appropriate targets for a site of DBS to relieve that type of pain (Hanajima et al. 2004, Pralong et al. 2004). Similarly local field potential responses associated with pain and recorded at the time of surgery may predict stimulation variables that relieve pain (low frequency relieved pain; greater than $50 \mathrm{~Hz}$ ) (Nandi et al. 2003).

\section{Deep Brain Stimulation for Depression and Obsessive Compulsive Disorder}

Although the studies are currently limited, DBS may in the future play a role in the treatment of refractory depression. A recent study found that DBS of the subgenual cingulate white matter improved mood in four of six people with treatment-resistant depression (Mayberg et al. 2005). The investigators targeted this region because they had previously demonstrated increased fluorodeoxyglucose (FDG) uptake measured with positron emission tomography (PET) in this area in people with depression. A single case report suggested stimulation of the inferior thalamic peduncle also may relieve depressive symptoms (Jimenez et al. 2005). Some have suggested the improvement of quality of life produced by STN DBS in patients with PD is primarily a reflection of the reduction of depression rather than the improvement in motor symptoms (Troster et al. 2003).

DBS of the bilateral anterior limbs of the internal capsules may reduce symptoms in OCD as found in three patients in one study (Gabriels et al. 2003). Another small, short-term, blinded study reported that two of four patients with OCD had either dramatic or moderate benefit after stimulation of the anterior limb of the internal capsule (Abelson et al. 2005). An 
open-label study found improvement of OCD in three of four patients (Cosyns et al. 2003).

Stimulation of the ventral caudate nucleus relieved depressive and OCD symptoms in an open-label case report of a single patient (Aouizerate et al. 2005).

\section{NEUROPHYSIOLOGY OF DEEP BRAIN STIMULATION}

Electrical stimulation of the brain has been shown to influence a variety of mechanisms involved in neuronal function and signaling. The sensitivity of different elements depends on the amplitude and temporal characteristics of the stimulation, physiologic properties of individual cells, geometry of the stimulus field, geometry of the stimulated elements, and possibly the underlying pathophysiology of different disease states. No single mechanism has emerged to account for the effect of DBS in different brain regions and in different diseases. However, it is becoming increasingly clear that different types of central nervous system (CNS) neurons possess different types of ion channels that may have different voltage-sensitive activation and inactivation properties. Therefore, the effect of DBS on neurons in different nuclei may be quite different. Nonetheless, the net effect resulting from different mechanisms may be comparable.

What elements of the CNS are affected by DBS under the usual clinical conditions? Although there are few data from human studies, general principles from work in other animals likely apply with few modifications. Ranck (1975) outlined many of the primary principles. One of the most important principles is the relationship between stimulus amplitude and duration. Weiss (1901) first described this relationship over 100 years ago. As current amplitude decreases, duration must increase to produce a constant effect. Similarly, as duration decreases, amplitude must increase to produce the same effect. For most neural elements, the form of the amplitude-duration curve is usually an exponential decay. The amplitude asymptote (threshold) at very long durations is called the rheobase. The relationship between the amplitude and pulse width is described by the following equation:

$$
\mathrm{I}_{\mathrm{th}}=\mathrm{I}_{\mathrm{rh}}\left(1+\tau_{\mathrm{ad}} / \mathrm{PW}\right) \text {, }
$$

where $\mathrm{I}_{\mathrm{th}}$ is the threshold current, $\mathrm{I}_{\mathrm{rh}}$ is the rheobase, $\tau_{\mathrm{ad}}$ is the chronaxie, and PW is the pulse width (duration). The chronaxie distinguishes different types of neural tissues or elements. The larger the chronaxie, the higher the current or pulse width must be to activate the neuronal element.

The chronaxie is substantially different for myelinated axons than for dendrites or cell bodies. Large myelinated CNS fibers have chronaxies of 30-200 $\mu$ s, whereas the chronaxie of dendrites and cell bodies may be in the 1-10-ms range (Ranck 1975). Comparable findings come from rat visual cortex where the chronaxie was $271 \mu$ s for subcortical white matter, $380 \mu$ s for cortical gray matter, and $15 \mathrm{~ms}$ for cortical cell bodies (Nowak \& Bullier 1998a). Thus, with usual stimulation parameters, postsynaptic responses from electrical stimulation of the cortical gray matter result from the activation of axons (initial segments or branches) rather than from cell bodies. These findings were confirmed and extended with experiments inducing depolarization block in cell bodies and the adjoining initial axon segment. Even when cells were blocked with NMDA-induced depolarization, stimulation in 
the neocortex elicited orthodromic reponses that were only reduced by $15 \%-20 \%$ from the control condition. Thus, postsynaptic effects of cortical stimulation are likely to result primarily from the activation of efferent axons (Nowak \& Bullier 1998b). A study to determine chronaxies in human VIM and GPi based on clinical efficacy found comparable results and suggested the effect of VIM DBS and GPi DBS is most likely mediated through afferent and efferent axons rather than through stimulation of cell bodies (Holsheimer et al. 2000).

The orientation of the cell body and axons in relation to current flow is an important determinant of responsiveness (Ranck 1975). For axons, the voltage gradient parallel to the axon is most important for eliciting a response. Gray matter and white matter have different resistivities as do myelinated and unmyelinated fibers. Thus the response to stimulation in a nucleus containing a mixture of elements is likely to be complex depending on the geometry of the neural elements, the stimulating electrode configuration, and the nucleus.

A final factor in determining responsiveness is the distance of the neural element from the electrode. Rheobase and chronaxie rise in proportion to the distance from the electrode (Holsheimer et al. 2000, Weiss 1901). Furthermore, currents from monopolar cathodes more than eight times threshold may block action potentials in axons. Thus at high currents nearby elements may be blocked, and distant elements may not receive sufficient stimulation, but elements in a intermediate "shell" will be activated.

The response to high-frequency stimulation in the context of therapeutic DBS has been studied most extensively in the ventral tier nuclei of the thalamus, theSTN, and the globus pallidus. Studies have suggested the physiologic response to high-frequency stimulation may differ across nuclei.

\section{Ventral Thalamic Nuclei}

The cerebellar afferent receiving zone of the thalamus (human VIM nucleus) has been the primary target for the treatment of tremor (Benabid et al. 1996) (Figure 1). These nuclei receive excitatory glutamatergic afferents from the deep cerebellar nuclei (Asanuma et al. 1983, Kultas-Ilinsky \& Ilinsky 1991), excitatory glutamatergic afferents from the cerebral cortex (Bromberg et al. 1981), and inhibitory GABAergic inputs from the reticular nucleus of the thalamus (Ambardekar et al. 1999, Ilinsky et al. 1999). In some species, they also receive inputs from GABAergic inhibitory interneurons (Kultas-Ilinsky et al. 1985). The output from these nuclei primarily targets motor areas of cerebral cortex (Hoover \& Strick 1999, Strick et al. 1993) but has also been shown to project to striatum (Hoshi et al. 2005, McFarland \& Haber 2001). Thus, although it is common to view VIM as a simple relay for information from the cerebellum to cerebral cortex, the synaptic connections are complex and DBS likely influences multiple elements.

Rodent in vitro thalamic slice preparations-To investigate the cellular mechanism by which DBS might work, Kiss and colleagues have employed a slice preparation from rat thalamus (Anderson et al. 2004, Kiss et al. 2002). The rat homologues of human VIM are the ventrolateral and ventroposterior nuclei. Using simulated DBS (sDBS) with variables comparable with that used in human DBS, Kiss et al (2002) have shown the effect of 
stimulation of ventral lateral ventral posterior thalamic nuclei (VL-VP) on neurons is both amplitude and frequency dependent. Response to stimulation was seen at frequencies above $20 \mathrm{~Hz}$, it increased with increasing stimulation frequency, and it reached a maximum at 200 $\mathrm{Hz}$. This is comparable with the frequency response characteristics of VIM DBS for ET (Ushe et al. 2004). When rhythmic pulse trains were injected into VL-VP neurons to simulate tremor-like bursting, sDBS eliminated the rhythmic firing (Kiss et al. 2002). At moderate currents, the rhythmic firing was replaced by nonrhythmic firing, but higher currents induced block and eliminated firing.

Using bipolar stimulation with parameters to mimic DBS (125 Hz, 60- $\mu$ s pulse width) and limit current spread to the VL-VP thalamus, 10-s trains of sDBS induced depolarization in VL-VP neurons (Anderson et al. 2004). For each neuron, the time course of the depolarization followed one of two pattern types. Type I (43 of 62 neurons) quickly reached a depolarization plateau and began to repolarize after $1 \mathrm{~s}$ with a moderate sustained depolarization of $8.2 \pm 6.1 \mathrm{mV}$ with no spike activity and no apparent excitatory postsynaptic potentials (EPSPs) after the initial depolarization. Type II (19 of 62 neurons) quickly reached a depolarization plateau but did not repolarize and maintained a larger plateau potential $(28.8 \pm 8 \mathrm{mV})$. Action potential occurrence in Type II responses was variable, usually with a period of quiescence followed by reemergence of firing. If stimulus trains were prolonged, both types of responses were maintained for up to $5 \mathrm{~min}$ of sDBS. Type I and Type II responses were thought to occur in the same cell type because the rat ventral thalamus is made of a homogeneous population of cells. Changing the stimulation current did not convert one response type to the other, and there was no relationship between response type and current amplitude or distance from stimulating electrode. Both types of depolarization responses were blocked by tetrodotoxin, kynurenate, or a mixture of 2amino-5-phosphonovaleric acid or 6,7-dinitroquinoxaline-2,3-dione. The blockade of presynaptic $\mathrm{Ca}^{2+}$ channels similarly blocked the depolarization response to sDBS. There was no effect of GABA blockade on either type of response. Thus, the depolarization response is dependent on action potential generation and glutamate neurotransmission via ionotropic receptors. The difference between Type I and Type II responses might reflect differences in the proportion of cortical and cerebellar afferents to individual cells in the slice preparation. The apparent lack of EPSPs during Type I responses suggests there might be a functional deafferentation. Type II responses would be associated with the loss of any rhythmic firing and might represent a mechanism by which pathological signals would be disrupted.

In addition to activating excitatory presynaptic terminals, sDBS in rat thalamic slice also produced increased excitability of thalamic neurons (Anderson et al. 2004). The threshold for triggering $\mathrm{Na}^{+}$-dependent action potentials was decreased by sDBS, even in the presence of ionotropic glutamate blockade, causing a $30 \%$ increased probability of firing action potentials in response to injected depolarizing currents. The decreased threshold was not a result of changes in membrane resistance. These nonsynaptic effects were dependent on current and distance from the stimulating electrode. Thus, regardless of presynaptic effects, the increased excitability of cell bodies suggests there also may be increased excitability of efferent axons. 
The limitations of the rat thalamic slice preparation include the following: (a) spontaneous afferent activity is lost; $(b)$ any pathological changes associated with neurologic disorders will not be represented; and (c) GABAergic inhibitory interneurons are present in human but not rat thalamus. The absence of inhibitory synaptic influences in the rat may limit the ability to extend these findings to human thalamus. In a preliminary report of human VIM neurons, 1-s trains of microstimulation at $100-300 \mathrm{~Hz}$ induced prolonged inhibition in $40 \%$ of recorded neurons (Dostrovsky et al. 2002). The inhibition was more common in neurons that were firing in bursts. The field of microstimulation effect is likely to be substantially smaller than that of typical DBS, and there is possibly a higher probability of activating local inhibitory neurons than excitatory afferents with microstimulation. Nonetheless, in VIM DBS, inhibitory synaptic mechanisms may be important contributors to the local effects of stimulation.

Subthalamic nucleus: The STN has become the most commonly used target for DBS in the treatment of PD (Rodriguez-Oroz et al. 2004) (Figure 1). The STN is an important node in basal ganglia circuits, serving as a major target for cortical afferents and also receiving multiple inputs from other basal ganglia components (Mink 1996, Parent \& Hazrati 1995). The STN receives glutamatergic excitatory afferents from the frontal lobe of the cerebral cortex (Monakow et al. 1978, Rouzaire-Dubois \& Scarnati 1987), GABAergic inhibitory afferents from the globus pallidus external segment (Bolam et al. 2000, Rouzaire-Dubois et al. 1980), and excitatory afferents from the parafascicular nucleus of the thalamus (Mouroux $\&$ Feger 1993). There are also inputs from the pedunculopontine nucleus (Lavoie \& Parent 1994) and from substantia nigra pars compacta (Cossette et al. 1999). The output from the STN is glutamatergic and excitatory to both segments of the globus, to the substantia nigra pars reticulata (SNr), and to the pedunculopontine area (Smith et al. 1990). Outputs appear to arise from different types of neurons, but classification schemes have not agreed on how many types of neurons exist in the STN. It appears there are at least two types of neurons in the STN as defined by baseline firing pattern and morphology (Magarinos-Ascone et al. 2002). Thus DBS in the STN has the potential to influence a variety of afferent and efferent targets and may have different effects on different neurons.

Rodent in vitro subthalamic nucleus slice preparations-The effect of highfrequency stimulation has been studied in rat STN slices by several investigators. The studies have involved different stimulation methodologies and have focused on different time periods making direct comparison difficult. Bipolar microstimulation $(0.1-1.0 \mu \mathrm{A})$ with trains of pulses produced a response that depended on the type of neuron (MagarinosAscone et al. 2002). The current was selected to produce subthreshold EPSPs in STN neurons. The two most frequently encountered neuron types were $(a)$ tonically active neurons that had a round soma and extensive radial dendritic field (68\%) and (b) bursting neurons with a triangular soma and less extensive dendritic field (25\%). Tonically active cells followed $130-\mathrm{Hz}$ stimulation for 5-15 s, then developed a bursting pattern, before ceasing to fire after $25 \mathrm{~s}$ of stimulation. At frequencies less than $90 \mathrm{~Hz}$, the cells followed for 5-15 s and then changed to bursting that persisted for the duration of the stimulation (40 s). Bursting cells responded to stimulation trains with a brief burst of action potentials followed by prolonged silence. There was no frequency dependence in bursting cells. A 
major limitation of this study was that the stimulation current was low and primarily affected presynaptic axons rather than cell bodies. Nevertheless, these findings suggest that presynaptic driving of STN neurons may fail at sustained high frequencies.

Beurrier et al. (2001) also reported a prolonged inactivation of STN neurons. They delivered bipolar stimulation to rat STN slice preparations in 1-min trains of $100-\mu$ sec pulses at a variety of frequencies. At frequencies $\leq 00 \mathrm{~Hz}$, there was no effect. At higher frequencies, there was a slowing of the post-stimulation firing rate and with frequencies between 166 and $250 \mathrm{~Hz}$, there was a complete and prolonged cessation of firing for an average of $5.8 \mathrm{~min}$. During the silent period, action potentials could still be evoked but at a slightly higher threshold. The silent period was not a result of hyperpolarization and was not influenced by chemicals that blocked ionotropic glutamate receptors or GABA receptors. Similarly, the blockade of presynaptic $\mathrm{Ca}^{2+}$ entry had no effect. During the silent period, the persistent $\mathrm{Na}^{+}$current was $99 \%$ blocked and T- and L-type $\mathrm{Ca}^{2+}$ currents were transiently depressed. Thus, it appeared the post-stimulation silence was a result of changes in membrane properties and not synaptic effects. It should be noted that prolonged post-stimulation silencing occurred only at frequencies higher than those that produce maximum benefit from STN DBS in PD patients (Moro et al. 2002).

Using stimulation parameters that more closely simulate clinical DBS, Garcia and colleagues (2003) have studied the effect of high-frequency stimulation in rat STN slice preparations from normal and dopamine-depleted rats. Monopolar stimulation with frequencies in the range of $80-185 \mathrm{~Hz}$ blocked spontaneous firing in STN neurons but induced stimulus-driven firing. The effect was seen regardless of whether the neurons were tonically active or bursting at baseline. The stimulus-driven firing was single spikes at lower currents or recurrent bursting at higher currents. The frequency of spikes within bursts followed reliably at $80 \mathrm{~Hz}$, had some failure at $135 \mathrm{~Hz}$, and only occurred every 2-3 pulses at $185 \mathrm{~Hz}$, firing with a mean intraburst frequency of $64-85 \mathrm{~Hz}$. The pattern of response varied among neurons but did not depend on the distance from the stimulating electrode, suggesting cell geometry in relation to the stimulation field might determine the response to stimulation (Garcia et al. 2003, Ranck 1975). There was no difference between the slices from intact or dopamine-depleted rats. The blockade of ionotropic or metabotropic glutamate receptors or of GABA receptors had no effect on the stimulus-driven firing. The stimulation-driven firing appeared to be a result of the activation of voltage-sensitive $\mathrm{Na}^{+}$ and L-type $\mathrm{Ca}^{2+}$ channels. However, consistent with the findings of Beurrier et al. (2001), after the stimulus train ended, STN neurons were silent for as long as several minutes. Thus, although there was likely to be a reduction of certain $\mathrm{Na}^{+}$and $\mathrm{Ca}^{2+}$ conductances, the stimulation trains were sufficient to overcome those to induce firing. In a subsequent study, Garcia et al. (2005) confirmed their previous findings and showed by systematically varying pulse width and stimulation frequency that combinations in the range used in human STN DBS never silenced STN neurons but rather drove firing. Combinations in the therapeutic range replaced baseline firing with stimulus-driven spikes in a stable oscillatory pattern time locked to the stimuli.

The lack of presynaptic effect with sDBS in STN slices contrasts with the results of Anderson et al. (2004) in thalamic slices. It is possible the difference relates to the method 
of stimulation. Garcia et al. (2003) used a monopolar configuration, and Anderson et al. (2004) used a bipolar configuration. When Anderson et al. (2004) used a monopolar configuration, they found a substantial reduction of presynaptic activation unless the current was increased three- to fivefold. It is also possible the predominately synaptic effect seen by Anderson and the predominately cellular membrane effect seen by Garcia are results of differences between the ventral thalamus and STN neurons.

In vivo animal studies-Although in vitro studies in slices can investigate synaptic and membrane physiology, they have limited ability to evaluate downstream effects of stimulation. Although few studies have been performed in intact experimental animals, the studies have indicated that DBS may activate efferent axons independent of any local synaptic or cellular effects.

In urethane-anesthetized rats, high-frequency STN stimulation caused post-stimulation depression of firing in the majority of neurons (Benazzouz et al. 2000). It also caused an inhibition of the majority of neurons recorded in the $\mathrm{SNr}$ and an increase in the majority of cells recorded in the ventrolateral thalamus. However, this study was limited by the inability to record during the time of stimulation, so all results were during the post-stimulation period. Nevertheless, in anesthetized rats, trains of high-frequency stimulation appear to cause a prolonged post-stimulation inactivation of STN neurons, and postsynaptic effects were consistent with inactivation of the excitatory STN to SNr projection.

In rats anesthetized with chloral hydrate, Maurice et al. (2003) investigated the effect of high-frequency (50-200-Hz) STN stimulation on spontaneous SNr firing and on $\mathrm{SNr}$ activity evoked by motor cortex stimulation. Low intensity microstimulation $(20-80 \mu \mathrm{A})$ at

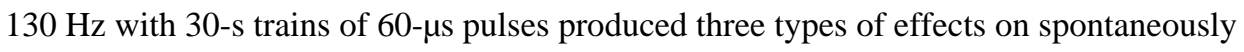
active SNr neurons. The firing of 84 of $129 \mathrm{SNr}$ cells was inhibited by an average of $79 \%$. The amount of inhibition was the same for frequencies ranging from 50-200 Hz. The inhibition was blocked by the application of the GABA antagonist bicuculline. Because the projection from the $\mathrm{STN}$ to the $\mathrm{SNr}$ is entirely excitatory, it is likely the stimulation activated inhibitory striatonigral or pallidonigral fibers (Windels et al. 2005). Excitation was seen in 28 of $129 \mathrm{SNr}$ cells with firing rates increasing up to $400 \%$. In 13 cells, inhibition was seen at low-stimulation currents and excitation was seen at higher currents. Excitatory responses were frequency dependent, increasing in a linear relationship for stimulation frequencies from 50 to $130 \mathrm{~Hz}$. These responses were likely a result of the direct activation of subthalamonigral neurons or axons. Twenty of 129 neurons were activated antidromically, suggesting the stimulation effect was not confined to STN but spread to the nigrothalamic pathway.

In the absence of STN stimulation, motor cortex stimulation typically elicits a triphasic response in $\mathrm{SNr}$ neurons with early excitation, inhibition, then late excitation. The early excitation is mediated by the activation of the excitatory projection from the STN to the SNr and the inhibition by the activation of inhibitory striatonigral neurons ("direct pathway"), and the late excitation is mediated by the disinhibition of subthalamonigral neurons ("indirect pathway"). In SNr neurons inhibited by STN stimulation, the early and late excitatory phases of cortically evoked activity were inhibited by $56 \%$ and $35 \%$, respectively, 
consistent with the activation of inhibitory inputs to the SNr. In $\mathrm{SNr}$ neurons excited by STN stimulation, both the early and late excitation were completely blocked during STN stimulation but the inhibitory response was preserved. Thus, high-frequency STN stimulation blocks the transmission of information through the STN. In summary, these results show that STN stimulation can activate multiple pathways but also that highfrequency STN stimulation activates excitatory projections from the STN to the SNr. Furthermore, STN stimulation blocks the flow of information through the STN, potentially preventing aberrant signals from being propogated in disease states. Indeed, STN stimulation in rats rendered cataleptic with dopamine antagonists reverses abnormal patterns in SNr neurons (Degos et al. 2005).

Two studies of the DBS effect on downstream neurons have been performed in monkeys (Hashimoto et al. 2003, Kita et al. 2005). Using a scaled-down version of the DBS electrode used clinically, Hashimoto et al. (2003) studied the effect of low- and high-frequency STN stimulation on pallidal neuron firing in 1-methyl-4-phenyl-1,2,3,6-tetrahydropyridine (MPTP) treated parkinsonian monkeys (Hashimoto et al. 2003). Stimulation at $136 \mathrm{~Hz}$ reliably reduced parkinsonian signs when sufficient current was delivered. Neurons in both the external pallidum (GPe) and GPi were recorded during stimulation at 2, 136, and $157 \mathrm{~Hz}$ with both effective and ineffective voltages. Short latency, multiphasic responses with alternating periods of inhibition and excitation were seen in GPe and GPi neurons following $2-\mathrm{Hz}$ STN stimulation. These short-latency responses also were present at $136-\mathrm{Hz}$ stimulation, voltages effective for the alleviation of parkinsonian signs. The later components of the response were obscured by stimulation at $157 \mathrm{~Hz}$, but the early components remained intact. The response persisted for up to $5 \mathrm{~min}$ of stimulation, producing a significant increase in mean discharge rate and a stimulus-synchronized regular firing pattern in the majority of GPe and GPi neurons (Figure 2). The preservation of the response pattern and overall increase in firing rate indicated that high-frequency STN stimulation using clinically relevant DBS parameters causes the activation of STN efferent fibers. The multiphasic response pattern suggests there was di- and trisynaptic activation of other components of basal ganglia circuitry. There was also evidence for antidromic activation of some GPe neurons. Kita et al. (2005) reported comparable results using shorter bursts of stimulation (10 pulses at $100 \mathrm{~Hz}$ ) but found that more complex disynaptic responses in the GPi exceeded simple monosynaptic excitation.

Human studies-Human studies have been performed in patients undergoing DBS electrode implantation for the treatment of PD. Theses studies offer the advantage of being able to study physiology in the relevant disease state using stimulation parameters that elicit clinical benefit. However, there are constraints as to what can be studied. Thus most recordings have been made in the region of stimulation and not in downstream structures.

Using paired electrodes separated by $600 \mu \mathrm{m}$, Filali et al. (2004) recorded the activity of STN neurons in response to brief trains $(500 \mathrm{~ms})$ of high-frequency STN stimulation. Their artifact suppression method precluded recording for several milliseconds after each pulse. However, following stimulus trains at 100-300 Hz, 25 of 60 STN cells were inhibited. No post-stimulus change in firing rate was observed in the other 35 cells. In 15 cells it was possible to detect inhibition during the train; 13 of these were inhibited. Furthermore, 8 of 
the 25 inhibited neurons also were inhibited by single pulses. Welter et al. (2004) confirmed these results by recording 21 STN cells during high-frequency STN stimulation trains of 20$\mathrm{s}$ duration. Fifteen of the 21 cells had decreased firing, and six had complete cessation of firing during the stimulation period. No increases were seen.

Globus pallidus: The GPi is the second most commonly used DBS target for the treatment of PD (Anderson et al. 2005) and is increasingly targeted for DBS treatment of dystonia (Vidailhet et al. 2005). The GPi is one of the primary output nuclei of the basal ganglia and is considered the main output representation of limb movements (Mink 1996). The GPi receives excitatory glutamatergic afferents from the STN (Hazrati \& Parent 1992, Rinvik \& Ottersen 1993), inhibitory GABAergic afferents from striatum (Kita \& Kitai 1988), inhibitory inputs from the GPe (Bolam \& Smith 1992), and nigral dopamine afferents (Smith et al. 1989). The inhibitory GABAergic output of the GPi projects to the ventral anterior and ventral lateral thalamus, intralaminar thalamus, and the pedunculopontine area (Parent \& De Bellefeuille 1982). Owing to its size and geometry, the effect of stimulation in the GPi is more likely to be restricted to the nucleus, but the potential remains for the possible spread to adjacent structures and pathways, especially the GPe and internal capsule.

The rodent homologue of GPi is the entopeduncular nucleus, which is embedded in the internal capsule. Thus it is not possible to simulate GPi DBS in slice preparations or in whole brain studies in rodents without confounding effects from stimulating fibers of passage.

In vivo animal studies of GPi stimulation-In an MPTP parkinsonian monkey, stimulation of the anterior GPi with 20-s trains of 100-120-Hz stimulation reduced the activity in 48 of $56 \mathrm{GPi}$ neurons recorded during the stimulation trains (Boraud et al. 1996). No activity increases were reported. In that animal, the GPi firing rate increased above normal baseline rates in response to MPTP treatment. High-frequency GPi stimulation reduced the average firing rate to normal range. No cells were completely inhibited.

In a subsequent study, Bar-Gad et al. (2004) recorded GPi activity during microstimulation of the GPi using short trains of high-frequency stimuli (10-40 pulse). They also reported an overall decrease in GPi firing rates but also reported some increases. Analysis with a higher temporal resolution revealed a complex locking of responses to the stimuli in most neurons. The locking displayed a stereotypical temporal structure consisting of three phases: an initial excitation followed by an inhibition and a second excitation. These data suggest the response of local neurons to high-frequency stimulation is complex. However, only short trains were used in that study and the response to chronic high-frequency stimulation may be different.

Anderson et al. (2003) recorded the activity of neurons in the pallidal-receiving zone of the thalamus during short trains $(<10 \mathrm{~s})$ of $120-\mathrm{Hz}$ stimulation in nonparkinsonian monkeys. Thirty-three of 73 recorded thalamic neurons were inhibited by high-frequency GPi stimulation, and seven were excited (Figure 3). At least one of the excitation responses recorded during stimulation also evoked muscle contraction at the contralateral shoulder, suggesting spread to the internal capsule. Low-amplitude stimulation produced inhibition 
but did not block movement-related firing increases; however, higher amplitude stimulation did block these movement-related changes. These data suggest that in addition to any effect on GPi cell bodies, high-frequency GPi stimulation activates efferent axons. Furthermore, stimulation changes baseline firing rates but also has the potential to disrupt normal (or abnormal) task-related patterns of activity in postsynaptic cells.

Human studies of GPi stimulation-In human subjects undergoing the implantation of GPi DBS electrodes, Dostrovsky et al. (2000) recorded the response of GPi neurons to lowfrequency $(5-50-\mathrm{Hz})$, low-amplitude stimulation delivered 250-600 $\mu \mathrm{m}$ from the recording site. The response in 22 of 23 cells was inhibition lasting 15-25 ms after each pulse, consistent with the activation of presynaptic inhibitory terminals. At higher frequencies up to $300 \mathrm{~Hz}$, stimulus trains produced decreased firing but did not completely block firing.

Pralong et al. (2003) reported the response of thalamic neurons to GPi DBS in a unique situation. A patient with postanoxic dystonia had previously undergone the implantation of GPi DBS electrodes without benefit. The patient subsequently consented to thalamic stimulation, in the putative pallidal-receiving zone. While recording prior to implantation of the thalamic DBS electrodes, the authors examined the response of seven thalamic neurons to GPi DBS while the patient was anesthetized with propofol. Four tonically active cells were inhibited by GPi stimulation; three low frequency cells did not change. Although limited, these results are consistent with those reported by Anderson et al. (2003) in the monkey.

Release of neurotransmitters by deep brain stimulation: An early study suggested that high-frequency stimulation of the STN in rodents increases extracellular glutamate in the GPi and a downstream target of STN projections, and that release may be dependent upon stimulation frequency (Windels et al. 2003). Although a similar increase was not found in humans with PD, there was an increase in cyclic guanosine monophosphate (cGMP) in the GPi (Stefani et al. 2005). Interestingly Windels et al. (2005) found that high-frequency STN stimulation in vivo in rats increased GABA in the $\mathrm{SNr}$, and this effect was abolished by ibotenic acid lesioning of the globus pallidus. STN DBS also increases extracellular striatal glutamate and GABA in rats (Windels et al. 2003). Together these findings support the notion that STN DBS drives output neurons. A similar effect may be important for other sites of stimulation. For example, the effects of high-frequency stimulation of thalamic slices were blocked by glutamate receptor antagonists (Anderson et al. 2004).

PET measures of striatal [11C]raclopride uptake did not change with STN DBS, suggesting release of striatal dopamine did not change enough to produce either an increased striatal [11C]raclopride uptake (evidence of reduced competition from less released dopamine) or a decreased striatal [11C]raclopride (suggesting increased release of striatal dopamine) (Hilker et al. 2003). This contrasts with a previous rodent study indicating that STN DBS increases striatal dopamine release (Meissner et al. 2002) in both normal and denervated (nigrostriatal lesioned) rats (Bruet et al. 2001). 


\section{Synthesis of Neurophysiologic Data}

Differences in techniques, anatomy, cell type, and experimental setting limit the ability to make direct comparisons across the studies reviewed above. However, several conclusions are possible. (a) High-frequency stimulation affects multiple elements, including afferent axons, cell bodies, efferent axons, and fibers of passage. (b) The stimulated elements may differ depending on the anatomy of the target (e.g., the VIM thalamus, STN, GPi, or others). (c) The effects may vary depending on the intrinsic physiologic properties of the targeted cells (Anderson et al. 2004, Do \& Bean 2003). (d) The effects vary with frequency, amplitude, pulse width, and duration of the spike trains. (e) Stimulation of the STN releases glutamate from excitatory efferent neurons. $(f)$ The net effect on distant targets, whether monosynaptic or polysynaptic, may be independent of local effects. Thus local cells may be inhibited by the activation of inhibitory afferents or by the effects on intrinsic ion conductances, but the efferent axons may still be activated. In the studies that have examined the effect of high-frequency stimulation on downstream targets, the finding is most consistent with the activation of efferent axons either directly or through activation of local cell bodies to axon initial segments (Anderson et al. 2003, Hashimoto et al. 2003, Pralong et al. 2003). Although the data supporting this conclusion come from a mixture of stimulation in rodents, MPTP parkinsonian monkeys, normal monkeys, and a single anesthetized patient, the conclusion is also supported by computer models (McIntyre \& Grill 2002) and by human functional imaging work (see below).

\section{FUNCTIONAL IMAGING OF DEEP BRAIN STIMULATION-INDUCED CHANGES IN BRAIN CIRCUITS}

\section{Positron Emission Tomography}

PET measurements of blood flow responses to DBS has been used to identify changes in brain pathways (Aiko et al. 1987, Black et al. 1997, Blandini et al. 1999, Ceballos-Baumann et al. 1999, Feiwell et al. 1999, Tempel \& Perlmutter 1993). This strategy based on the notion that blood flow and metabolism are closely coupled to neuronal activity, at least under normal physiologic conditions (Gold \& Lauritzen 2002, Lauritzen 2001). Another key underlying assumption is that changes in local blood flow reflect changes in neuronal activity in target synaptic fields, including local interneurons, rather than changes in efferent activity (Gold \& Lauritzen 2002, Lauritzen 2001, Logothetis et al. 2001, McCulloch 1982, Raichle 1987, Schwartz et al. 1979). Thus a PET-measured blood flow response could indicate a change of input to that region or alterations in local interneuronal activity. It also is assumed that the only change between stimulus conditions (typically either off, on at optimal setting, or in some studies on with suboptimal settings) is the change in DBS. Any behavioral change can confound interpretation of measured changes in blood flow because the behavioral change may induce cortical blood responses that do not reflect direct effects of DBS but rather may reflect sensory feedback from changes in motor activity (Figure 4). This is particularly troublesome in PD studies because people with PD may have changes in resting tremor or other active muscle activity such as dystonia that may occur at rest. This potential confound requires careful observation and measurement of motor activity during PETs and then appropriate exclusion of such confounded scans. 
The first question that may be addressed with imaging is how stimulation alters selected brain pathways. More specifically, it may be possible to distinguish whether the effect of stimulation is to either increase or decrease the net output from a site of stimulation. We found that thalamic stimulation in people with ET increases blood flow in downstream targets of thalamic output, consistent with stimulation increasing the activity of projection neurons (Perlmutter et al. 2002). The people with ET had their arms at rest with no tremor during the scans with DBS on or off, so there was no behavioral change that could have produced sensory feedback. Surface electromyography on the limbs, continuous videography, and direct observation during the scans ensured there was no tremor or other extraneous movements during the scans. Haslinger et al. (2003) also found that VIM DBS in ET patients at rest increased regional blood flow at the site of stimulation and in the sensorimotor cortex in an increasing fashion corresponding to increasing stimulus frequency or amplitude. In contrast, a similar study of thalamic stimulation in people with PD found that cortical flow was decreased with DBS, but changes in behavior such as the reduction or elimination of resting tremor could reduce the flow as a result of this behavioral change (Fukuda et al. 2004).

Deiber et al. (1993) used PET to compare blood flow during parkinsonian tremor with VIM DBS off, during parkinsonian tremor with ineffective DBS settings (frequency lowered to 50-65 Hz) and during suppressed tremor with effective settings. Subtraction analysis of effective DBS with suppressed tremor minus ineffective DBS revealed reduced flow in the cerebellum, but this could be a result of the effects of reduced feedback from the presence of the tremor rather than a direct change induced by VIM DBS. Ineffective DBS minus the stimulator off condition revealed reduction of homolateral cerebral cortex flow (likely a result of the effects of the ineffective stimulation because there were no other changes between the two conditions). However, this small study of six subjects was limited by an older data analysis method that did not consider differences in regional variance in the PET data.

Neuroimaging studies in PD are more challenging as a result of the potential behavioral changes with stimulators either on or off. For example, we had to eliminate at least one-third of the PETs in PD patients because the subjects had either tremor or other potentially confounding extraneous movements during a 1-min blood flow scan in a study of DBS responses to STN stimulation (Hershey et al. 2003). Having done that, we then could demonstrate that STN DBS increased blood flow in the thalamus and reduced blood flow in cortical areas (Hershey et al. 2003). These data are consistent with the hypothesis that STN stimulation increases firing of STN output neurons, which increases the inhibition of thalamocortical projections, ultimately decreasing blood flow in cortical targets.

Increased thalamic metabolism also was found in another study with bilateral STN DBS in eight people with PD (Hilker et al. 2004). However, this FDG PET study also reported increased FDG uptake in multiple cortical regions, and the investigators did not mention behavioral changes that likely occurred during the two different PET conditions: on and off bilateral STN DBS. Therefore, this and other PET or single photon emission computed tomography studies (Hilker et al. 2002, 2004; Fukuda et al. 2001b; Sestini et al. 2002) that do not adequately assess and consider behavioral condition of subjects during PETs must be 
interpreted with a great deal of caution. Monitoring surface electromyographic activity, directly observing and videotaping all subjects during PETs, and excluding scans with these confounds may help to avoid these potential pitfalls (Hershey et al. 2003).

Several studies have reported changes in regional blood flow during motor tasks with and without DBS of the STN or the GPi, but these do not directly identify the effects of DBS alone (Fukuda et al. 2001a, 2002; Strafella et al. 2003). In these types of studies there are two potential behavioral confounds. First, if the motor task is performed differently with the stimulators on versus off, then the sensory feedback to the brain and subsequent flow or metabolic response might be altered. Second, even the same performance may be actuated differently if there is different resistance or power needed to perform the same task in the two DBS conditions. Thus, these types of studies must be interpreted cautiously.

\section{Functional Magnetic Resonance Imaging Studies of Deep Brain Stimulation}

Could fMRI of blood oxygenation level-dependent signals be used for these studies? Rezai et al. (1999) demonstrated the feasibility of this approach for thalamic stimulation, which produces clinical effects within $30 \mathrm{~s}$ of starting stimulation. They studied patients after the implantation of the electrode into the thalamus but before surgical placement of the pulse generator, requiring a study between the two surgeries. However, this approach does not permit an opportunity to optimize programming of DBS or to let any lesion effect of surgery abate, which may substantially limit its practicality. Furthermore, because the time to maximal benefit from STN DBS in people with PD takes as much as 30 min or longer, this would be difficult for an fMRI study that requires repeated on-off cycles because of issues of shifting baseline. Near-infrared spectroscopy measurements found considerable variations in the blood oxygenation in frontal cortex during either thalamic or GPi stimulation, which raises questions about the potential of fMRI for these studies (Murata et al. 2000, Sakatani et al. 1999). Thorough evaluation to ensure safety must also be done prior to exposing patients to this research procedure. At least one study found that structural MRI in people with implanted DBS electrodes can be done safely (Uitti et al. 2002), but others suggest that substantial caution must be exercised when doing magnetic resonance scanning with active DBS electrodes in the magnetic resonance field (Georgi et al. 2004). fMRI pulse sequences produce larger magnitude magnetic fields that may pose additional risks for active DBS contacts and pulse generators. However, it is possible to do fMRI studies with externalized leads and pulse generators removed from the magnetic resonance field (Stefurak et al. 2003), but this permits only peri-operative studies with limited time for patient evaluations. Finally, one must be careful during such research studies as a slightly frayed wire carries an increased risk of heating surrounding tissue.

A single case report suggested that fMRI blood oxygenation level-dependent signals increased in different cortical regions depending upon the position within the region of the STN of the stimulating electrode and associated behavioral response (Stefurak et al. 2003). Specifically, stimulation through the left active electrode in the left inferior STN provided good motor benefit and increased flow in primary motor areas but decreased flow in supplementary motor area. Such strategies may help to identify functional connections 
among basal ganglia and cortical loops. However, interpretation of these types of studies is critically dependent upon accurate identification of the site and effects of DBS.

\section{CONCLUSIONS}

DBS has the potential to provide substantial benefit for a variety of neuropsychiatric conditions. Despite the marked clinical benefit, we still have much to learn about the mechanism of action of DBS. However, we have come a long way in our understanding of the effects of DBS on neurons, transmitters, and brain pathways. Physiologic and imaging studies support the notion that the net effect of DBS is to increase the firing of neurons projecting from the site of stimulation. This may be mediated primarily via the stimulation of axons rather than cell bodies.

If DBS drives efferent axons, how does it exert its clinical effect? DBS seems to mimic the effect of destructive lesions, suggesting that despite the activation of efferent axons, there is interruption of information flow or processing. The data of Maurice et al. (2003) from rats and of Anderson et al. (2003) from monkeys indicate that high-frequency stimulation can prevent the normal pattern activity whether driven by electrical cortical stimulation or related to a limb-movement task. If normal circuits are disrupted in this way, it makes sense that abnormal circuit activity also would be disrupted. Indeed, STN DBS has been shown to eliminate abnormal rhythmic oscillation of GPi local field potentials (Brown et al. 2004), and impairing abnormal firing patterns may be more critical than changing net firing rates (McIntyre \& Thakor 2002, Vitek 2002).

Future studies may continue to distinguish variations in the effects of DBS on different nuclei and different neuronal cell types. Furthermore, patients with implanted DBS electrodes afford an outstanding opportunity to investigate behavioral effects of functional circuits (Hershey et al. 2004, Schroeder et al. 2003), but it will be critical to carefully control behavioral confounds to properly interpret such studies.

\section{Acknowledgments}

The authors thank Dr. Tamara Hershey for expert assistance and providing Figure 4. This research was supported by NIH grants NS050425, NS39913, NS39821, and NS41509 and the Greater St. Louis Chapter of the American Parkinson Disease Association (APDA), the APDA Center for Advanced PD Research at Washington University, the Barnes-Jewish Hospital Foundation (the Jack Buck Fund and the Elliot H. Stein Family Fund), the Missouri Chapter of the Dystonia Medical Research Foundation, and the Sam \& Barbara Murphy Fund.

\section{Glossary}

$\begin{array}{ll}\text { DBS } & \text { deep brain stimulation } \\ \text { ET } & \text { essential tremor } \\ \text { PD } & \text { Parkinson disease } \\ \text { VIM } & \text { ventral intermediate nucleus of the thalamus } \\ \text { STN } & \text { subthalamic nucleus } \\ \text { GPi } & \text { internal segment of the globus pallidus }\end{array}$


fMRI functional magnetic resonance imaging

PET positron emission tomography

\section{LITERATURE CITED}

Abelson JL, Curtis GC, Sagher O, Albucher RC, Harrigan M, et al. Deep brain stimulation for refractory obsessive-compulsive disorder. Biol Psychiatry. 2005; 57:510-16. [PubMed: 15737666]

Aiko Y, Shima F, Hosokawa S, Kato M, Kitamura K. Altered local cerebral glucose utilization induced by electrical stimulations of the thalamic sensory and parafascicular nuclei in rats. Brain Res. 1987; 408:47-56. [PubMed: 3594230]

Ambardekar AV, Ilinsky IA, Forestl W, Bowery NG, Kultas-Ilinsky K. Distribution and properties of GABA(B) antagonist [3H]CGP 62349 binding in the rhesus monkey thalamus and basal ganglia and the influence of lesions in the reticular thalamic nucleus. Neuroscience. 1999; 93:1339-47. [PubMed: 10501458]

Anderson ME, Postupna N, Ruffo M. Effects of high-frequency stimulation in the internal globus pallidus on the activity of thalamic neurons in the awake monkey. J Neurophysiol. 2003; 89:115060. [PubMed: 12574488]

Anderson T, Hu B, Pittman Q, Kiss ZH. Mechanisms of deep brain stimulation: an intracellular study in rat thalamus. J Physiol. 2004; 559:301-13. [PubMed: 15218068]

Anderson VC, Burchiel KJ, Hogarth P, Favre J, Hammerstad JP. Pallidal vs subthalamic nucleus deep brain stimulation in Parkinson disease. Arch Neurol. 2005; 62:554-60. [PubMed: 15824252]

Aouizerate B, Martin-Guehl C, Cuny E, Guehl D, Amieva H, et al. Deep brain stimulation of the ventral striatum in the treatment of obsessive-compulsive disorder and major depression. Med Sci (Paris). 2005; 21:811-13. [PubMed: 16197896]

Asanuma C, Thach WT, Jones EG. Distribution of cerebellar terminations and their relation to other afferent terminations in the ventral lateral thalamic region of the monkey. Brain Res. 1983; 286:237-65. [PubMed: 6189561]

Bar-Gad I, Elias S, Vaadia E, Bergman H. Complex locking rather than complete cessation of neuronal activity in the globus pallidus of a 1-methyl-4-phenyl-1,2,3,6-tetrahydropyridine-treated primate in response to pallidal microstimulation. J Neurosci. 2004; 24:7410-19. [PubMed: 15317866]

Bartholow R. Experimental investigations into the functions of the human brain. Am J Med Sci. 1874; 67:305-13.

Bastian AJ, Kelly VE, Revilla FJ, Perlmutter JS, Mink JW. Different effects of unilateral versus bilateral subthalamic nucleus stimulation on walking and reaching in Parkinson's disease. Mov Disord. 2003; 18:1000-7. [PubMed: 14502667]

Benabid AL, Benazzouz A, Hoffmann D, Limousin P, Krack P, Pollak P. Long-term electrical inhibition of deep brain targets in movement disorders. Mov Disord. 1998; 13(Suppl. 3):119-25. [PubMed: 9827607]

Benabid AL, Pollak P, Gao D, Hoffmann D, Limousin P, et al. Chronic electrical stimulation of the ventralis intermedius nucleus of the thalamus as a treatment of movement disorders. J Neurosurg. 1996; 84:203-14. [PubMed: 8592222]

Benabid AL, Pollak P, Gervason C, Hoffmann D, Gao DM, et al. Long-term suppression of tremor by chronic stimulation of the ventral intermediate thalamic nucleus. Lancet. 1991; 337:403-6. [PubMed: 1671433]

Benazzouz A, Gao DM, Ni ZG, Piallat B, Bouali-Benazzouz R, Benabid AL. Effect of high-frequency stimulation of the subthalamic nucleus on the neuronal activities of the substantia nigra pars reticulata and ventrolateral nucleus of the thalamus in the rat. Neuroscience. 2000; 99:289-95. [PubMed: 10938434]

Bergstrom MR, Johansson GG, Laitinen LV, Sipponen P. Electrical stimulation of the thalamic and subthalamic area in cerebral palsy. Acta Physiol Scand. 1966; 67:208-13. [PubMed: 5336446] 
Berney A, Vingerhoets F, Perrin A, Guex P, Villemure JG, et al. Effect on mood of subthalamic DBS for Parkinson's disease: a consecutive series of 24 patients. Neurology. 2002; 59:1427-29. [PubMed: 12427897]

Beurrier C, Bioulac B, Audin J, Hammond C. High-frequency stimulation produces a transient blockade of voltage-gated currents in subthalamic neurons. J Neurophysiol. 2001; 85:1351-56. [PubMed: 11287459]

Bittar RG, Kar-Purkayastha I, Owen SL, Bear RE, Green A, et al. Deep brain stimulation for pain relief: a meta-analysis. J Clin Neurosci. 2005; 12:515-19. [PubMed: 15993077]

Black KJ, Gado MH, Perlmutter JS. PET measurement of dopamine D2 receptor-mediated changes in striatopallidal function. J Neurosci. 1997; 17:3168-77. [PubMed: 9096151]

Blandini F, Conti G, Martignoni E, Colangelo V, Nappi G, et al. Modifications of local cerebral metabolic rates for glucose and motor behavior in rats with unilateral lesion of the subthalamic nucleus. J Cereb Blood Flow Metab. 1999; 19:149-54. [PubMed: 10027770]

Bolam JP, Hanley JJ, Booth PA, Bevan MD. Synaptic organisation of the basal ganglia. J Anat. 2000; 196(Pt. 4):527-42. [PubMed: 10923985]

Bolam JP, Smith Y. The striatum and the globus pallidus send convergent synaptic inputs onto single cells in the entopeduncular nucleus of the rat: a double anterograde labeling study combined with postembedding immunocytochemistry for GABA. J Comp Neurol. 1992; 321:456-76. [PubMed: 1380517]

Boraud T, Bezard E, Bioulac B, Gross C. High frequency stimulation of the internal globus pallidus (GPi) simultaneously improves parkinsonian symptoms and reduces the firing frequency of GPi neurons in the MPTP-treated monkey. Neurosci Lett. 1996; 215:17-20. [PubMed: 8880743]

Brice J, McLellan L. Suppression of intention tremor by contingent deep-brain stimulation. Lancet. 1980; 1:1221-22. [PubMed: 6104038]

Bromberg MB, Penney JBJ, Stephenson BS, Young AB. Evidence for glutamate as the neurotransmitter of corticothalamic and corticorubral pathways. Brain Res. 1981; 215:369-74. [PubMed: 6167322]

Brown P, Mazzone P, Oliviero A, Altibrandi MG, Pilato F, et al. Effects of stimulation of the subthalamic area on oscillatory pallidal activity in Parkinson's disease. Exp Neurol. 2004; 188:480-90. [PubMed: 15246847]

Bruet N, Windels F, Bertrand A, Feuerstein C, Poupard A, Savasta M. High frequency stimulation of the subthalamic nucleus increases the extracellular contents of striatal dopamine in normal and partially dopaminergic denervated rats. J Neuropathol Exp Neurol. 2001; 60:15-24. [PubMed: 11202172]

Burchiel KJ, Anderson VC, Favre J, Hammerstad JP. Comparison of pallidal and subthalamic nucleus deep brain stimulation for advanced Parkinson's disease: results of a randomized, blinded pilot study. Neurosurgery. 1999; 45:1375-82. [PubMed: 10598706]

Castelnau P, Cif L, Valente EM, Vayssiere N, Hemm S, et al. Pallidal stimulation improves pantothenate kinase-associated neurodegeneration. Ann Neurol. 2005; 57:738-41. [PubMed: 15852393]

Ceballos-Baumann AO, Boecker H, Bartensetin P, von Falkenhayn I, Riescher H, et al. A positron emission tomographic study of subthalamic nucleus stimulation in Parkinson's disease: enhanced movement-related activity of motor-association cortex and decreased motor cortex resting activity. Arch Neurol. 1999; 56:997-1003. [PubMed: 10448806]

Cooper IS. Effect of chronic stimulation of anterior cerebellum on neurological disease. Lancet. 1973; 1:206. [PubMed: 4118825]

Cooper IS, Riklan M, Amin I, Waltz JM, Cullinan T. Chronic cerebellar stimulation in cerebral palsy. Neurology. 1976; 26:744-53. [PubMed: 1084966]

Cossette M, Levesque M, Parent A. Extrastriatal dopaminergic innervation of human basal ganglia. Neurosci Res. 1999; 34:51-54. [PubMed: 10413327]

Cosyns P, Gabriels L, Nuttin B. Deep brain stimulation in treatment refractory obsessive compulsive disorder. Verh K Acad Geneeskd Belg. 2003; 65:385-99. [PubMed: 14964038] 
Coubes P, Cif L, El Fertit H, Hemm S, Vayssiere N, et al. Electrical stimulation of the globus pallidus internus in patients with primary generalized dystonia: long-term results. J Neurosurg. 2004; 101:189-94. [PubMed: 15309907]

Degos B, Deniau JM, Thierry AM, Glowinski J, Pezard L, Maurice N. Neuroleptic-induced catalepsy: electrophysiological mechanisms of functional recovery induced by high-frequency stimulation of the subthalamic nucleus. J Neurosci. 2005; 25:7687-96. [PubMed: 16107655]

Deiber MP, Pollak P, Passingham R, Landais P, Gervason C, et al. Thalamic stimulation and suppression of parkinsonian tremor. Evidence of a cerebellar deactivation using positron emission tomography. Brain. 1993; 116(Pt. 1):267-79. [PubMed: 8453462]

Diamond A, Jankovic J. The effect of deep brain stimulation on quality of life in movement disorders. J Neurol Neurosurg Psychiatr. 2005; 76:1188-93. [PubMed: 16107348]

Diederich NJ, Alesch F, Goetz C. Visual hallucinations induced by deep brain stimulation in Parkinson's disease. Clin Neuropharmacol. 2000; 23:287-89. [PubMed: 11154099]

Diederich NJ, Kalteis K, Stamenkovic M, Pieri V, Alesch F. Efficient internal pallidal stimulation in Gilles de la Tourette syndrome: a case report. Mov Disord. 2005; 20:1496-99. [PubMed: 16037913]

Do MT, Bean BP. Subthreshold sodium currents and pacemaking of subthalamic neurons: modulation by slow inactivation. Neuron. 2003; 39:109-20. [PubMed: 12848936]

Dostrovsky JO, Levy R, Wu JP, Hutchison WD, Tasker RR, Lozano AM. Mirostimulation-induced inhibition of neuronal firing in human globus pallidus. J Neurophysiol. 2000; 84:570-74. [PubMed: 10899228]

Dostrovsky JO, Patra S, Hutchison WD, Palter VN, Filali M, Lozano AM. Effects of stimulation in human thalamus on activity of nearby thalamic neurons. Society Neurosci Abstr. 2002; 62:14.

Eltahawy HA, Saint-Cyr J, Giladi N, Lang AE, Lozano AM. Primary dystonia is more responsive than secondary dystonia to pallidal interventions: outcome after pallidotomy or pallidal deep brain stimulation. Neurosurgery. 2004; 54:613-19. [PubMed: 15028135]

Feiwell RJ, Black KJ, McGee-Minnich LA, Snyder AZ, MacLeod AMK, Perlmutter JS. Diminished regional cerebral blood flow response to vibration in patients with blepharospasm. Neurology. 1999; 52:291-97. [PubMed: 9932946]

Ferrarin M, Rizzone M, Bergamasco B, Lanotte M, Recalcati M, et al. Effects of bilateral subthalamic stimulation on gait kinematics and kinetics in Parkinson's disease. Exp Brain Res. 2005; 160:51727. [PubMed: 15502989]

Filali M, Hutchison WD, Palter VN, Lozano AM, Dostrovsky JO. Stimulation-induced inhibition of neuronal firing in human subthalamic nucleus. Exp Brain Res. 2004; 156:274-81. [PubMed: 14745464]

Flaherty AW, Williams ZM, Amirnovin R, Kasper E, Rauch SL, et al. Deep brain stimulation of the anterior internal capsule for the treatment of Tourette syndrome: technical case report. Neurosurgery. 2005; 57:E403. [PubMed: 16234657]

Franzini A, Ferroli P, Leone M, Broggi G. Stimulation of the posterior hypothalamus for treatment of chronic intractable cluster headaches: first reported series. Neurosurgery. 2003; 52:1095-99. [PubMed: 12699552]

Fritsch G, Hitzig E. Uber die elektrische Erregbarkeit des Grosshirns. Arch Anat Physiol. 1870; 37:300-32.

Fukuda M, Barnes A, Simon ES, Holmes A, Dhawan V, et al. Thalamic stimulation for parkinsonian tremor: correlation between regional cerebral blood flow and physiological tremor characteristics. Neuroimage. 2004; 21:608-15. [PubMed: 14980563]

Fukuda M, Ghilardi MF, Carbon M, Dhawan V, Ma Y, et al. Pallidal stimulation for parkinsonism: improved brain activation during sequence learning. Ann Neurol. 2002; 52:144-52. [PubMed: 12210783]

Fukuda M, Mentis M, Ghilardi MF, Dhawan V, Antonini A, et al. Functional correlates of pallidal stimulation for Parkinson's disease. Ann Neurol. 2001a; 49:155-64. [PubMed: 11220735]

Fukuda M, Mentis MJ, Ma Y, Dhawan V, Antonini A, et al. Networks mediating the clinical effects of pallidal brain stimulation for Parkinson's disease: a PET study of resting-state glucose metabolism. Brain. 2001b; 124:1601-9. [PubMed: 11459751] 
Gabriels L, Cosyns P, Nuttin B, Demeulemeester H, Gybels J. Deep brain stimulation for treatmentrefractory obsessive-compulsive disorder: psychopathological and neuropsychological outcome in three cases. Acta Psychiatr Scand. 2003; 107:275-82. [PubMed: 12662250]

Garcia L, Audin J, D’Alessandro G, Bioulac B, Hammond C. Dual effect of high-frequency stimulation on subthalamic neuron activity. J Neurosci. 2003; 23:8743-51. [PubMed: 14507974]

Garcia L, D’Alessandro G, Fernagut PO, Bioulac B, Hammond C. Impact of high-frequency stimulation parameters on the pattern of discharge of subthalamic neurons. J Neurophysiol. 2005; 94:3662-69. [PubMed: 16148275]

Georgi JC, Stippich C, Tronnier VM, Heiland S. Active deep brain stimulation during MRI: a feasibility study. Magn Reson Med. 2004; 51:380-88. [PubMed: 14755664]

Gold L, Lauritzen M. Neuronal deactivation explains decreased cerebellar blood flow in response to focal cerebral ischemia or suppressed neocortical function. Proc Natl Acad Sci USA. 2002; 99:7699-704. [PubMed: 12032346]

Hanajima R, Dostrovsky JO, Lozano AM, Hutchison WD, Davis KD, et al. Somatosensory evoked potentials (SEPs) recorded from deep brain stimulation (DBS) electrodes in the thalamus and subthalamic nucleus (STN). Clin Neurophysiol. 2004; 115:424-34. [PubMed: 14744585]

Hashimoto T, Elder CM, Okun MS, Patrick SK, Vitek JL. Stimulation of the subthalamic nucleus changes the firing pattern of pallidal neurons. J Neurosci. 2003; 23:1916-23. [PubMed: 12629196]

Haslinger B, Boecker H, Buchel C, Vesper J, Tronnier VM, et al. Differential modulation of subcortical target and cortex during deep brain stimulation. Neuroimage. 2003; 18:517-24. [PubMed: 12595204]

Hassler R, Riechart T, Munginer F, Umbach W, Ganglberger JA. Physiological observations in stereotaxic operations in extrapyramidal motor disturbances. Brain. 1960; 83:337-50. [PubMed: 13852002]

Hazrati LN, Parent A. Convergence of subthalamic and striatal efferents at pallidal level in primates: an anterograde double-labeling study with biocytin and PHA-L. Brain Res. 1992; 569:336-40. [PubMed: 1371710]

Hershey T, Revilla F, Wernle A, Schneider-Gibson P, Dowling J, Perlmutter JS. Stimulation of STN impairs aspects of cognitive control in PD. Neurology. 2004; 62:1110-14. [PubMed: 15079009]

Hershey T, Revilla FJ, Wernle A, McGee-Minnich L, Antenor JV, et al. Cortical and subcortical blood flow effects of subthalamic nucleus stimulation in PD. Neurology. 2003; 61:816-21. [PubMed: 14504327]

Herzog J, Reiff J, Krack P, Witt K, Schrader B, et al. Manic episode with psychotic symptoms induced by subthalamic nucleus stimulation in a patient with Parkinson's disease. Mov Disord. 2003; 18:1382-84. [PubMed: 14639687]

Hilker R, Voges J, Ghaemi M, Lehrke R, Rudolf J, et al. Deep brain stimulation of the subthalamic nucleus does not increase the striatal dopamine concentration in parkinsonian humans. Mov Disord. 2003; 18:41-48. [PubMed: 12518299]

Hilker R, Voges J, Thiel A, Ghaemi M, Herholz K, et al. Deep brain stimulation of the subthalamic nucleus versus levodopa challenge in Parkinson's disease: measuring the on- and off-conditions with FDG-PET. J Neural Transm. 2002; 109:1257-64. [PubMed: 12373559]

Hilker R, Voges J, Weisenbach S, Kalbe E, Burghaus L, et al. Subthalamic nucleus stimulation restores glucose metabolism in associative and limbic cortices and in cerebellum: evidence from a FDG-PET study in advanced Parkinson's disease. J Cereb Blood Flow Metab. 2004; 24:7-16. [PubMed: 14688612]

Holsheimer J, Demeulemeester H, Nuttin B, de Sutter P. Identification of the target neuronal elements in electrical deep brain stimulation. Eur J Neurosci. 2000; 12:4573-77. [PubMed: 11122371]

Hoover JE, Strick PL. The organization of cerebellar and basal ganglia outputs to primary motor cortex as revealed by retrograde transneuronal transport of herpes simplex virus type 1. J Neurosci. 1999; 19:1446-63. [PubMed: 9952421]

Hoshi E, Tremblay L, Feger J, Carras PL, Strick PL. The cerebellum communicates with the basal ganglia. Nat Neurosci. 2005; 8:1491-93. [PubMed: 16205719]

Hosobuchi Y, Adams JE, Rutkin B. Chronic thalamic stimulation for the control of facial anesthesia dolorosa. Arch Neurol. 1973; 29:158-61. [PubMed: 4591720] 
Houeto JL, Karachi C, Mallet L, Pillon B, Yelnik J, et al. Tourette's syndrome and deep brain stimulation. J Neurol Neurosurg Psychiatr. 2005; 76:992-95. [PubMed: 15965209]

Ilinsky IA, Ambardekar AV, Kultas-Ilinsky K. Organization of projections from the anterior pole of the nucleus reticularis thalami (NRT) to subdivisions of the motor thalamus: light and electron microscopic studies in the rhesus monkey. J Comp Neurol. 1999; 409:369-84. [PubMed: 10379824]

Jaggi JL, Umemura A, Hurtig HI, Siderowf AD, Colcher A, et al. Bilateral stimulation of the subthalamic nucleus in Parkinson's disease: surgical efficacy and prediction of outcome. Stereotact Funct Neurosurg. 2004; 82:104-14. [PubMed: 15305083]

Jahanshahi M, Ardouin CM, Brown RG, Rothwell JC, Obeso J, et al. The impact of deep brain stimulation on executive function in Parkinson's disease. Brain. 2000; 123(Pt. 6):1142-54. [PubMed: 10825353]

Jimenez F, Velasco F, Salin-Pascual R, Hernandez JA, Velasco M, et al. A patient with a resistant major depression disorder treated with deep brain stimulation in the inferior thalamic peduncle. Neurosurgery. 2005; 57:585-93. [PubMed: 16145540]

Katayama Y, Yamamoto T, Kobayashi K, Kasai M, Oshima H, Fukaya C. Motor cortex stimulation for phantom limb pain: comprehensive therapy with spinal cord and thalamic stimulation. Stereotact Funct Neurosurg. 2001a; 77:159-62. [PubMed: 12378068]

Katayama Y, Yamamoto T, Kobayashi K, Kasai M, Oshima H, Fukaya C. Motor cortex stimulation for poststroke pain: comparison of spinal cord and thalamic stimulation. Stereotact Funct Neurosurg. 2001b; 77:183-86. [PubMed: 12378074]

Kiss ZH, Doig K, Eliasziw M, Ranawaya R, Suchowersky O. The Canadian multicenter trial of pallidal deep brain stimulation for cervical dystonia: preliminary results in three patients. Neurosurg Focus. 2004; 17:E5. [PubMed: 15264774]

Kiss ZH, Mooney DM, Renaud L, Hu B. Neuronal response to local electrical stimulation in rat thalamus: physiological implications for mechanisms of deep brain stimulation. Neuroscience. 2002; 113:137-43. [PubMed: 12123692]

Kita H, Kitai ST. Glutamate decarboxylase immunoreactive neurons in rat neostriatum: their morphological types and populations. Brain Res. 1988; 447:346-52. [PubMed: 3390703]

Kita H, Tachibana Y, Nambu A, Chiken S. Balance of monosynaptic excitatory and disynaptic inhibitory responses of the globus pallidus induced after stimulation of the subthalamic nucleus in the monkey. J Neurosci. 2005; 25:8611-19. [PubMed: 16177028]

Koller WC, Lyons KE, Wilkinson SB, Pahwa R. Efficacy of unilateral deep brain stimulation of the VIM nucleus of the thalamus for essential head tremor. Mov Disord. 1999a; 14:847-50. [PubMed: 10495050]

Koller WC, Lyons KE, Wilkinson SB, Troster AI, Pahwa R. Long-term safety and efficacy of unilateral deep brain stimulation of the thalamus in essential tremor. Mov Disord. 2001; 16:46468. [PubMed: 11391740]

Koller WC, Pahwa PR, Lyons KE, Wilkinson SB. Deep brain stimulation of the VIM nucleus of the thalamus for the treatment of tremor. Neurology. 2000; 55:S29-33. [PubMed: 11188972]

Koller WC, Pahwa R, Lyons KE, Albanese A. Surgical treatment of Parkinson's disease. J Neurol Sci. 1999b; 167:1-10. [PubMed: 10500254]

Kultas-Ilinsky K, Ilinsky IA. Fine structure of the ventral lateral nucleus (VL) of the Macaca mulatta thalamus: cell types and synaptology. J Comp Neurol. 1991; 314:319-49. [PubMed: 1723998]

Kultas-Ilinsky K, Ribak CE, Peterson GM, Oertel WH. A description of the GABAergic neurons and axon terminals in the motor nuclei of the cat thalamus. J Neurosci. 1985; 5:1346-69. [PubMed: 3998825]

Kumar K, Toth C, Nath RK. Deep brain stimulation for intractable pain: a 15-year experience. Neurosurgery. 1997; 40:736-46. [PubMed: 9092847]

Kumar R, Dagher A, Hutchison WD, Lang AE, Lozano AM. Globus pallidus deep brain stimulation for generalized dystonia: clinical and PET investigation. Neurology. 1999a; 53:871-74. [PubMed: 10489059] 
Kumar R, Lozano AM, Kim YJ, Hutchison WD, Sime E, et al. Double-blind evaluation of subthalamic nucleus deep brain stimulation in advanced Parkinson's disease. Neurology. 1998a; 51:850-55. [PubMed: 9748038]

Kumar R, Lozano AM, Montgomery E, Lang AE. Pallidotomy and deep brain stimulation of the pallidum and subthalamic nucleus in advanced Parkinson's disease. Mov Disord. 1998b; 13(Suppl. 1):73-82. [PubMed: 9613722]

Kumar R, Lozano AM, Sime E, Halket E, Lang AE. Comparative effects of unilateral and bilateral subthalamic nucleus deep brain stimulation. Neurology. 1999b; 53:561-66. [PubMed: 10449121]

Kumar R, Lozano AM, Sime E, Lang AE. Long-term follow-up of thalamic deep brain stimulation for essential and parkinsonian tremor. Neurology. 2003; 61:1601-04. [PubMed: 14663050]

Lauritzen M. Relationship of spikes, synaptic activity, and local changes of cerebral blood flow. J Cereb Blood Flow Metab. 2001; 21:1367-83. [PubMed: 11740198]

Lavoie B, Parent A. Pedunculopontine nucleus in the squirrel monkey: distribution of cholinergic and monoaminergic neurons in the mesopontine tegmentum with evidence for the presence of glutamate in cholinergic neurons. J Comp Neurol. 1994; 344:190-209. [PubMed: 7915726]

Leone M, Franzini A, D’Andrea G, Broggi G, Casucci G, Bussone G. Deep brain stimulation to relieve drug-resistant SUNCT. Ann Neurol. 2005; 57:924-27. [PubMed: 15929061]

Levy RM, Lamb S, Adams JE. Treatment of chronic pain by deep brain stimulation: long term followup and review of the literature. Neurosurgery. 1987; 21:885-93. [PubMed: 3325851]

Logothetis NK, Pauls J, Augath M, Trinath T, Oeltermann A. Neurophysiological investigation of the basis of the fMRI signal. Nature. 2001; 412:150-57. [PubMed: 11449264]

Loher TJ, Burgunder JM, Weber S, Sommerhalder R, Krauss JK. Effect of chronic pallidal deep brain stimulation on off period dystonia and sensory symptoms in advanced Parkinson's disease. J Neurol Neurosurg Psychiatr. 2002; 73:395-99. [PubMed: 12235307]

Lozano AM, Kumar R, Gross RE, Giladi N, Hutchison WD, et al. Globus pallidus internus pallidotomy for generalized dystonia. Mov Disord. 1997; 12:865-70. [PubMed: 9399208]

Lyons KE, Pahwa R. Long-term benefits in quality of life provided by bilateral subthalamic stimulation in patients with Parkinson disease. J Neurosurg. 2005; 103:252-55. [PubMed: 16175854]

Lyons KE, Wilkinson SB, Overman J, Pahwa R. Surgical and hardware complications of subthalamic stimulation: a series of 160 procedures. Neurology. 2004; 63:612-16. [PubMed: 15326230]

Magarinos-Ascone C, Pazo JH, Macadar O, Buno W. High-frequency stimulation of the subthalamic nucleus silences subthalamic neurons: a possible cellular mechanism in Parkinson's disease. Neuroscience. 2002; 115:1109-17. [PubMed: 12453483]

Maurice N, Thierry AM, Glowinski J, Deniau JM. Spontaneous and evoked activity of substantia nigra pars reticulata neurons during high-frequency stimulation of the subthalamic nucleus. J Neurosci. 2003; 23:9929-36. [PubMed: 14586023]

Mayberg HS, Lozano AM, Voon V, McNeely HE, Seminowicz D, et al. Deep brain stimulation for treatment-resistant depression. Neuron. 2005; 45:651-60. [PubMed: 15748841]

McCulloch, J. Mapping functional alterations in the CNS with [14C]deoxyglucose. In: Iverson, LL.; Iverson, SD.; Snyder, SH., editors. Handbook of Psychopharmacology: New Techniques in Psychopharmacology. New York: Plenum; 1982. p. 321-410.

McFarland NR, Haber SN. Organization of thalamostriatal terminals from the ventral motor nuclei in the macaque. J Comp Neurol. 2001; 429:321-36. [PubMed: 11116223]

McIntyre CC, Grill WM. Extracellular stimulation of central neurons: influence of stimulus waveform and frequency on neuronal output. J Neurophysiol. 2002; 88:1592-604. [PubMed: 12364490]

McIntyre CC, Thakor NV. Uncovering the mechanisms of deep brain stimulation for Parkinson's disease through functional imaging, neural recording, and neural modeling. Crit Rev Biomed Eng. 2002; 30:249-81. [PubMed: 12739751]

Meissner W, Harnack D, Paul G, Reum T, Sohr R, et al. Deep brain stimulation of subthalamic neurons increases striatal dopamine metabolism and induces contralateral circling in freely moving 6-hydroxydopamine-lesioned rats. Neurosci Lett. 2002; 328:105-8. [PubMed: 12133566] 
Mink JW. The basal ganglia: focused selection and inhibition of competing motor programs. Prog Neurobiol. 1996; 50:381-425. [PubMed: 9004351]

Monakow KH, Akert K, Kunzle H. Projections of the precentral motor cortex and other cortical areas of the frontal lobe to the subthalamic nucleus in the monkey. Exp Brain Res. 1978; 33:395-403. [PubMed: 83239]

Moro E, Esselink RJ, Xie J, Hommel M, Benabid AL, Pollak P. The impact on Parkinson's disease of electrical parameter settings in STN stimulation. Neurology. 2002; 59:706-13. [PubMed: 12221161]

Mouroux M, Feger J. Evidence that the parafascicular projection to the subthalamic nucleus is glutamatergic. Neuroreport. 1993; 4:613-15. [PubMed: 8102257]

Murata Y, Katayama Y, Oshima H, Kawamata T, Yamamoto T, et al. Changes in cerebral blood oxygenation induced by deep brain stimulation: study by near-infrared spectroscopy (NIRS). Keio J Med. 2000; 49(Suppl. 1):A61-63. [PubMed: 10750340]

Nandi D, Aziz T, Carter H, Stein J. Thalamic field potentials in chronic central pain treated by periventricular gray stimulation-a series of eight cases. Pain. 2003; 101:97-107. [PubMed: 12507704]

Nowak LG, Bullier J. Axons, but not cell bodies, are activated by electrical stimulation in cortical gray matter. I. Evidence from chronaxie measurements. Exp Brain Res. 1998a; 118:477-88. [PubMed: 9504843]

Nowak LG, Bullier J. Axons, but not cell bodies, are activated by electrical stimulation in cortical gray matter. II. Evidence from selective inactivation of cell bodies and axon initial segments. Exp Brain Res. 1998b; 118:489-500. [PubMed: 9504844]

Nutt JG, Rufener SL, Carter JH, Anderson VC, Pahwa R, et al. Interactions between deep brain stimulation and levodopa in Parkinson's disease. Neurology. 2001; 57:1835-42. [PubMed: 11723273]

Ohye C, Kubota K, Hongo T, Nagao T, Narabayashi H. Ventrolateral and subventrolateral thalamic stimulation. Arch Neurol. 1964; 11:427-34. [PubMed: 14196736]

Ondo W, Jankovic J, Schwartz K, Almaguer M, Simpson RK. Unilateral thalamic deep brain stimulation for refractory essential tremor and Parkinson's disease tremor. Neurology. 1998; 51:1063-69. [PubMed: 9781530]

Pahwa R, Wilkinson SB, Overman J, Lyons KE. Preoperative clinical predictors of response to bilateral subthalamic stimulation in patients with Parkinson's disease. Stereotact Funct Neurosurg. 2005; 83:80-83. [PubMed: 16006779]

Parent A, De Bellefeuille L. Organization of efferent projections from the internal segment of globus pallidus in primate as revealed by fluorescence retrograde labeling method. Brain Res. 1982; 245:201-13. [PubMed: 7127069]

Parent A, Hazrati LN. Functional anatomy of the basal ganglia. II. The place of subthalamic nucleus and external pallidum in basal ganglia circuitry. Brain Res Brain Res Rev. 1995; 20:128-54. [PubMed: 7711765]

Penfield W, Boldrey E. Somatic motor and sensory representation in the cerebral cortex of man as studied by electrical stimulation. Brain. 1937; 60:389-443.

Penn RD. Chronic cerebellar stimulation for cerebral palsy: a review. Neurosurgery. 1982; 10:116-21. [PubMed: 6977103]

Peppe A, Pierantozzi M, Altibrandi MG, Giacomini P, Stefani A, et al. Bilateral GPi DBS is useful to reduce abnormal involuntary movements in advanced Parkinson's disease patients, but its action is related to modality and site of stimulation. Eur J Neurol. 2001; 8:579-86. [PubMed: 11784342]

Perlmutter JS, Mink JW, Bastian AJ, Zackowski K, Hershey T, et al. Blood flow responses to deep brain stimulation of thalamus. Neurology. 2002; 15:1388-94. [PubMed: 12011286]

Pollak P, Fraix V, Krack P, Moro E, Mendes A, et al. Treatment results: Parkinson's disease. Mov Disord. 2002; 17(Suppl. 3):S75-83. [PubMed: 11948759]

Pralong E, Debatisse D, Maeder M, Vingerhoets F, Ghika J, Villemure JG. Effect of deep brain stimulation of GPI on neuronal activity of the thalamic nucleus ventralis oralis in a dystonic patient. Neurophysiol Clin. 2003; 33:169-73. [PubMed: 14519544] 
Pralong E, Pollo C, Bloch J, Villemure JG, Daniel RT, et al. Recording of ventral posterior lateral thalamus neuron response to contact heat evoked potential in patient with neurogenic pain. Neurosci Lett. 2004; 367:332-35. [PubMed: 15337260]

Putzke JD, Wharen REJ, Wszolek ZK, Turk MF, Strongosky AJ, Uitti RJ. Thalamic deep brain stimulation for tremor-predominant Parkinson's disease. Parkinsonism Relat Disord. 2003; 10:81-88. [PubMed: 14643997]

Raichle, ME. Circulatory and metabolic correlates of brain function in normal humans. In: Plum, F., editor. Handbook of Physiology: The Nervous System. Bethesda: Am Physiol Soc; 1987. p. 643-74.

Ranck JBJ. Which elements are excited in electrical stimulation of mammalian central nervous system: a review. Brain Res. 1975; 98:417-40. [PubMed: 1102064]

Rehncrona S, Johnels B, Widner H, Tornqvist AL, Hariz M, Sydow O. Long-term efficacy of thalamic deep brain stimulation for tremor: double-blind assessments. Mov Disord. 2003; 18:163-70. [PubMed: 12539209]

Rezai AR, Lozano AM, Crawley AP, Joy ML, Davis KD, et al. Thalamic stimulation and functional magnetic resonance imaging: localization of cortical and subcortical activation with implanted electrodes. Technical note. J Neurosurg. 1999; 90:583-90. [PubMed: 10067936]

Rinvik E, Ottersen OP. Terminals of subthalamonigral fibres are enriched with glutamate-like immunoreactivity: an electron microscopic, immunogold analysis in the cat. J Chem Neuroanat. 1993; 6:19-30. [PubMed: 7679908]

Rizzone M, Ferrarin M, Pedotti A, Bergamasco B, Bosticco E, et al. High-frequency electrical stimulation of the subthalamic nucleus in Parkinson's disease: kinetic and kinematic gait analysis. Neurol Sci. 2002; 23(Suppl. 2):S103-4. [PubMed: 12548364]

Rodriguez-Oroz MC, Zamarbide I, Guridi J, Palmero MR, Obeso JA. Efficacy of deep brain stimulation of the subthalamic nucleus in Parkinson's disease 4 years after surgery: double blind and open label evaluation. J Neurol Neurosurg Psychiatr. 2004; 75:1382-85. [PubMed: 15377681]

Rouzaire-Dubois B, Hammond C, Hamon B, Feger J. Pharmacological blockade of the globus palidusinduced inhibitory response of subthalamic cells in the rat. Brain Res. 1980; 200:321-29. [PubMed: 7417819]

Rouzaire-Dubois B, Scarnati E. Pharmacological study of the cortical-induced excitation of subthalamic nucleus neurons in the rat: evidence for amino acids as putative neurotransmitters. Neuroscience. 1987; 21:429-40. [PubMed: 2886955]

Russmann H, Ghika J, Combrement P, Villemure JG, Bogousslavsky J, et al. L-dopa-induced dyskinesia improvement after STN-DBS depends upon medication reduction. Neurology. 2004; 63:153-55. [PubMed: 15249627]

Sakatani K, Katayama Y, Yamamoto T, Suzuki S. Changes in cerebral blood oxygenation of the frontal lobe induced by direct electrical stimulation of thalamus and globus pallidus: a near infrared spectroscopy study. J Neurol Neurosurg Psychiatr. 1999; 67:769-73. [PubMed: 10567495]

Schoenen J, Di Clemente L, Vandenheede M, Fumal A, De Pasqua V, et al. Hypothalamic stimulation in chronic cluster headache: a pilot study of efficacy and mode of action. Brain. 2005; 128:94047. [PubMed: 15689358]

Schroeder U, Kuehler A, Hennenlotter A, Haslinger B, Tronnier VM, et al. Facial expression recognition and subthalamic nucleus stimulation. J Neurol Neurosurg Psychiatr. 2004; 75:64850. [PubMed: 15026519]

Schroeder U, Kuehler A, Lange KW, Haslinger B, Tronnier VM, et al. Subthalamic nucleus stimulation affects a frontotemporal network: a PET study. Ann Neurol. 2003; 54:445-50. [PubMed: 14520655]

Schwartz WJ, Smith CB, Davidsen L, Savaki H, Sokoloff L. Metabolic mapping of functional activity in the hypothalamo-neurohypophysial system of the rat. Science. 1979; 205:723-25. [PubMed: 462184] 
Sellal F, Hirsch E, Barth P, Blond S, Marescaux C. A case of symptomatic hemidystonia improved by ventroposterolateral thalamic electrostimulation. Mov Disord. 1993; 8:515-18. [PubMed: 8232364]

Sem-Jacobsen CW. Depth-electrographic observations related to Parkinson's disease. Recording and electrical stimulation in the area around the third ventricle. J Neurosurg. 1966; 24(Suppl):388402. [PubMed: 5324458]

Sestini S, Scotto di Luzio A, Ammannati F, De Cristofaro MTR, Passeri A, et al. Changes in regional cerebral blood flow caused by deep-brain stimulation of the subthalamic nucleus in Parkinson's disease. J Nucl Med. 2002; 43:725-32. [PubMed: 12050315]

Smith Y, Hazrati LN, Parent A. Efferent projections of the subthalamic nucleus in the squirrel monkey as studied by the PHA-L anterograde tracing method. J Comp Neurol. 1990; 294:306-23. [PubMed: 2332533]

Smith Y, Lavoie B, Dumas J, Parent A. Evidence for a distinct nigropallidal dopaminergic projection in the squirrel monkey. Brain Res. 1989; 482:381-86. [PubMed: 2565144]

Spiegel EA, Wycis HT. Thalamotomy and pallidotomy for treatment of choreic movements. Acta Neurochir (Wien). 1952; 2:417-22. [PubMed: 12976060]

Spiegel EA, Wycis HT, Marks M, Lee AJ. Stereotaxic apparatus for operations on the human brain. Science. 1947; 106:349-50. [PubMed: 17777432]

Stefani A, Fedele E, Galati S, Pepicelli O, Frasca S, et al. Subthalamic stimulation activates internal pallidus: evidence from cGMP microdialysis in PD patients. Ann Neurol. 2005; 57:448-52. [PubMed: 15732123]

Stefurak T, Mikulis D, Mayberg H, Lang AE, Hevenor S, et al. Deep brain stimulation for Parkinson's disease dissociates mood and motor circuits: a functional MRI case study. Mov Disord. 2003; 18:1508-16. [PubMed: 14673888]

Strafella AP, Dagher A, Sadikot AF. Cerebral blood flow changes induced by subthalamic stimulation in Parkinson's disease. Neurology. 2003; 60:1039-42. [PubMed: 12654980]

Strick, PL.; Hoover, JE.; Mushiake, H. Evidence for 'output channels' in the basal ganglia and cerebellum. In: Mano, N.; Hamada, I., editors. Role of the Cerebellum and Basal ganglia in Voluntary Movement. Amsterdam: Elsevier Science; 1993. p. 171-82.

Taha JM, Janszen MA, Favre J. Thalamic deep brain stimulation for the treatment of head, voice, and bilateral limb tremor. J Neurosurg. 1999; 91:68-72. [PubMed: 10389882]

Takeshita S, Kurisu K, Trop L, Arita K, Akimitsu T, Verhoeff NP. Effect of subthalamic stimulation on mood state in Parkinson's disease: evaluation of previous facts and problems. Neurosurg Rev. 2005; 28:179-86. [PubMed: 15827764]

Tasker RR, Vilela FO. Deep brain stimulation for neuropathic pain. Stereotact Funct Neurosurg. 1995; 65:122-24. [PubMed: 8916340]

Temel Y, Visser-Vandewalle V. Surgery in Tourette syndrome. Mov Disord. 2004; 19:3-14. [PubMed: 14743354]

Tempel LW, Perlmutter JS. Abnormal cortical responses in patients with writer's cramp. Neurology. 1993; 43:2252-57. [PubMed: 8232938]

Tirakotai W, Reigel T, Sure U, Rohlfs J, Gharabaghi A, et al. Image-guided motor cortex stimulation in patients with central pain. Minim Invas Neurosurg. 2005; 47:273-77.

Troster A, Fields JA, Wilkinson S, Pahwa R, Koller WC, Lyons KE. Effect of motor improvement on quality of life following subthalamic stimulation is mediated by changes in depressive symptomatology. Stereotact Funct Neurosurg. 2003; 80:43-47. [PubMed: 14745208]

Uitti RJ, Tsuboi Y, Pooley RA, Putzke JD, Turk MF, et al. Magnetic resonance imaging and deep brain stimulation. Neurosurgery. 2002; 51:1423-28. [PubMed: 12445347]

Ushe M, Mink JW, Revilla FJ, Wernle A, Schneider GP, et al. Effect of stimulation frequency on tremor suppression in essential tremor. Mov Disord. 2004; 19:1163-68. [PubMed: 15390071]

Vidailhet M, Vercueil L, Houeto JL, Krystkowiak P, Benabid AL, et al. Bilateral deep-brain stimulation of the globus pallidus in primary generalized dystonia. N Engl J Med. 2005; 352:459-67. [PubMed: 15689584] 
Visser-Vandewalle V, Temel Y, Boon P, Vreeling F, Colle H, et al. Chronic bilateral thalamic stimulation: a new therapeutic approach in intractable Tourette syndrome. Report of three cases. J Neurosurg. 2003; 99:1094-100. [PubMed: 14705742]

Visser-Vandewalle V, van der Linden C, Temel Y, Celik H, Ackermans L, et al. Long-term effects of bilateral subthalamic nucleus stimulation in advanced Parkinson disease: a four year follow-up study. Parkinsonism Relat Disord. 2005; 11:157-65. [PubMed: 15823480]

Vitek JL. Mechanisms of deep brain stimulation: excitation or inhibition. Mov Disord. 2002; 17:S6972. [PubMed: 11948757]

Vitek JL, Zhang J, Evatt M, Mewes K, DeLong MR, et al. GPi pallidotomy for dystonia: clinical outcome and neuronal activity. Adv Neurol. 1998; 78:211-19. [PubMed: 9750917]

Volkmann J, Allert N, Voges J, Weiss PH, Freund HJ, Sturm V. Safety and efficacy of pallidal or subthalamic nucleus stimulation in advanced PD. Neurology. 2001; 56:548-51. [PubMed: 11222806]

Weiss G. Sur la possiblite de rendre comparable entre eux les appareils servant a l'excitation electrique. Arch Ital Biol. 1901; 35:413-46.

Welter ML, Houeto JL, Bonnet AM, Bejjani PB, Mesnage V, et al. Effects of high-frequency stimulation on subthalamic neuronal activity in parkinsonian patients. Arch Neurol. 2004; 61:8996. [PubMed: 14732625]

Windels F, Bruet N, Poupard A, Feuerstein C, Bertrand A, Savasta M. Influence of the frequency parameter on extracellular glutamate and gamma-aminobutyric acid in substantia nigra and globus pallidus during electrical stimulation of subthalamic nucleus in rats. J Neurosci Res. 2003; 72:259-67. [PubMed: 12672001]

Windels F, Carcenac C, Poupard A, Savasta M. Pallidal origin of GABA release within the substantia nigra pars reticulata during high-frequency stimulation of the subthalamic nucleus. J Neurosci. 2005; 25:5079-86. [PubMed: 15901790]

Yoshor D, Hamilton WJ, Ondo W, Jankovic J, Grossman RG. Comparison of thalamotomy and pallidotomy for the treatment of dystonia. Neurosurgery. 2001; 48:818-24. [PubMed: 11322442] 


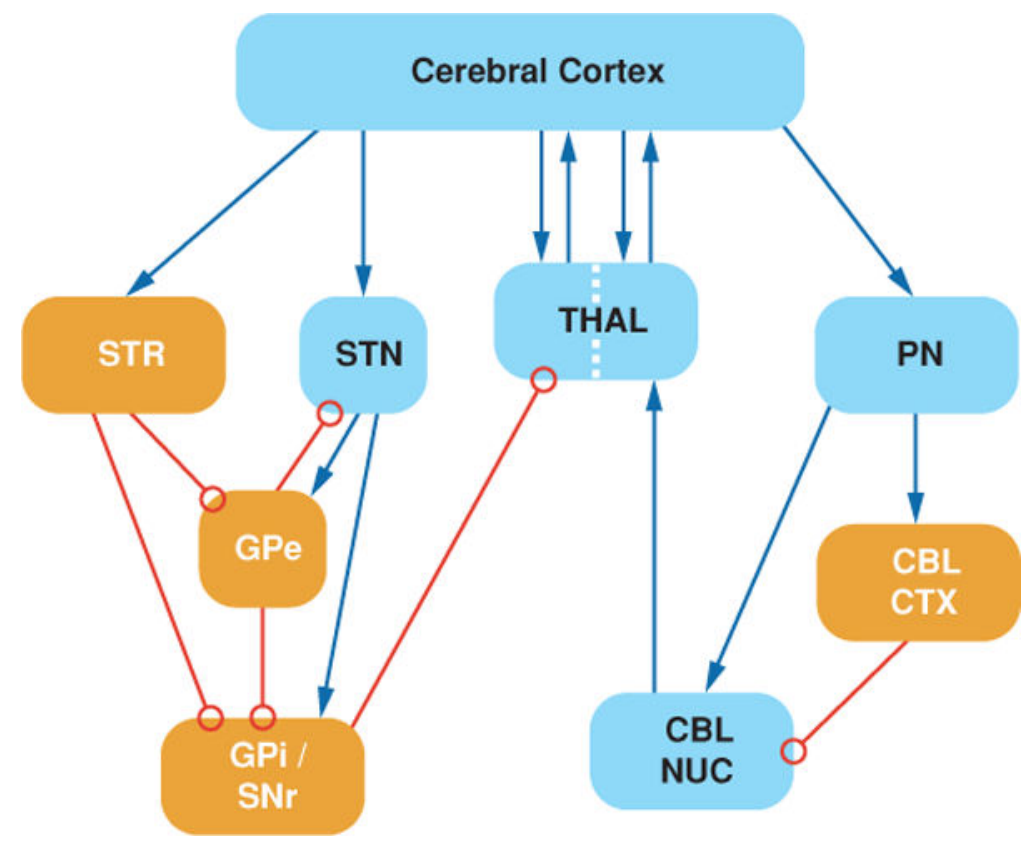

Figure 1.

Simplified schematic of subcortical motor systems circuitry. Blue arrows represent excitatory synapses, and open red circles represent inhibitory synapses. Dotted line across the thalamus indicates the segregation between striatal and cerebellar connections. $\mathrm{CBL}$ CTX, cerebellar cortex; CBL NUC, cerebellar nuclei; GPe, globus pallidus external segment; GPi, globus pallidus internal segment; PN, pontine nuclei; SNr, substantia nigra pare reticulate; STN, subthalamic nucleus; STR, striatum; THAL, thalamus. 

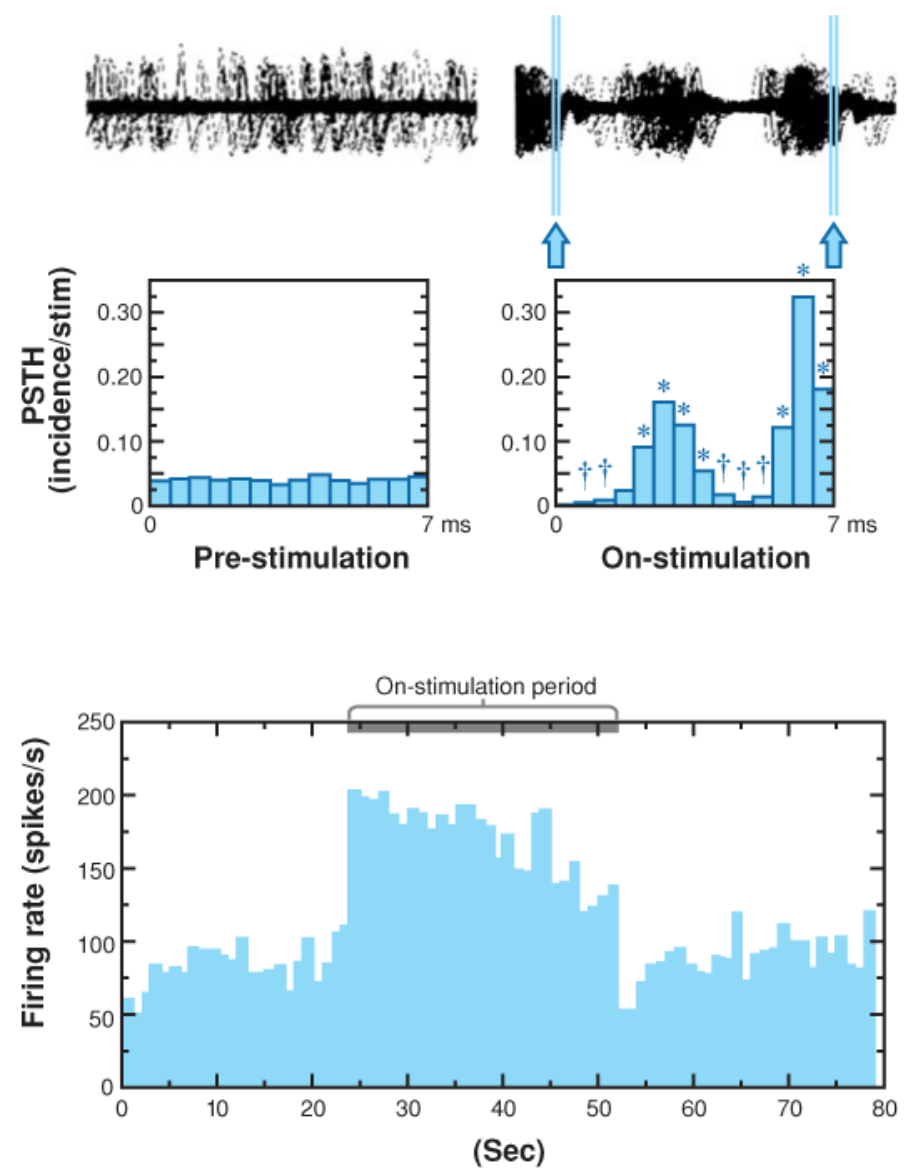

Figure 2.

The neuronal response of a GPi cell during subthalamic nucleus stimulation. Top trace shows analog signal overlays of 100 sweeps made by triggering at 10 -ms intervals in the prestimulation period and by triggering on the stimulation pulse in the on-stimulation period. Arrows indicate residual stimulation artifacts after artifact-template subtraction. Middle traces display peristimulus time histograms (PSTHs) reconstructed from successive 7.0-ms time periods in the prestimulation period and from the interstimulus periods in the onstimulation period. The first PSTH bin is omitted in the on-stimulation period because of signal saturation and residual stimulation artifacts. Asterisks represent significant increase at $p \leq 0.01$; Daggers represent significant decrease at $p \leq 0.01$; Wilcoxon signed rank test. Bottom plot represents the mean firing rate calculated every $1 \mathrm{~s}$ on the basis of the PSTH illustrating the time course of the firing rate. From Hashimoto et al. 2003. 

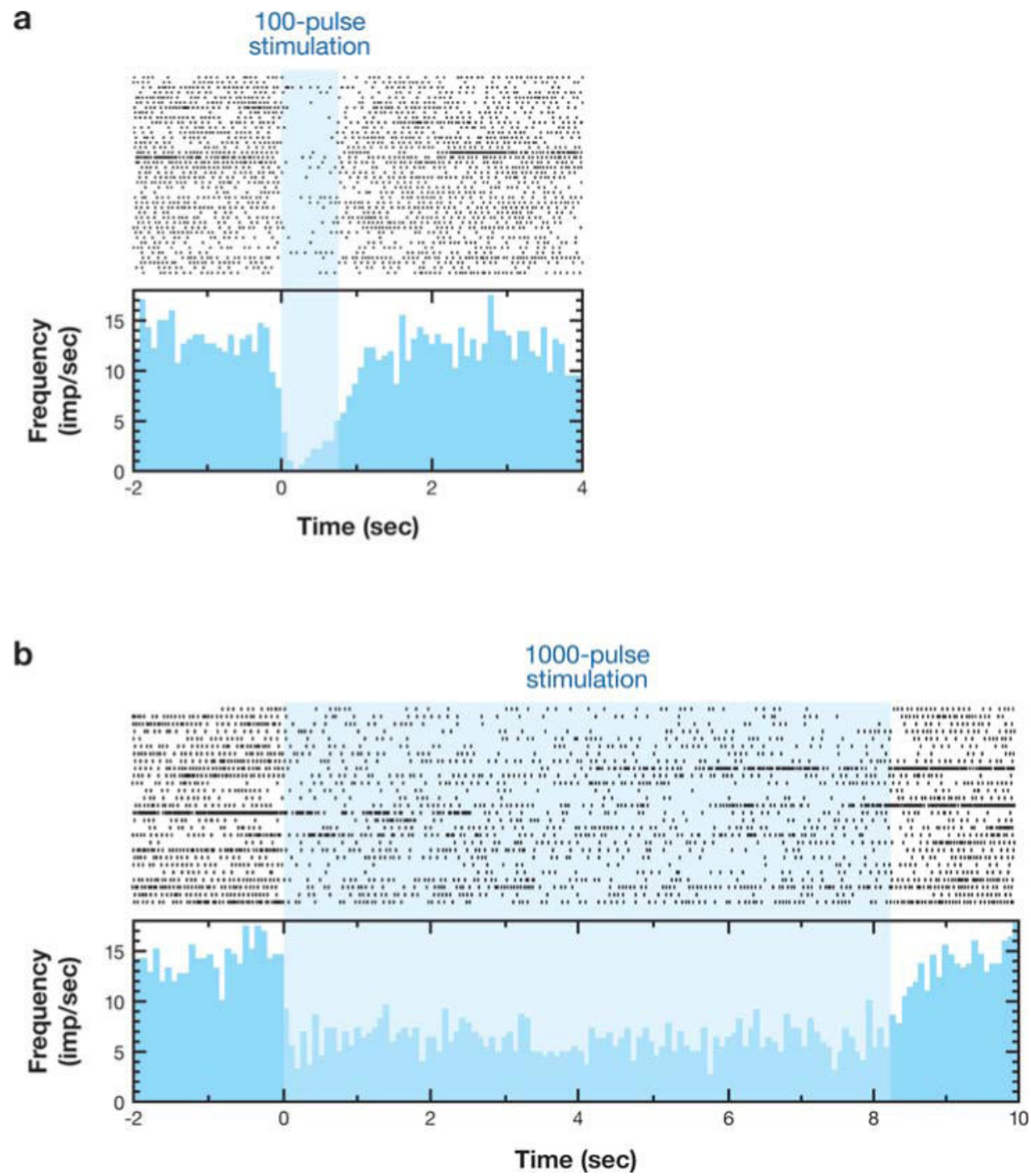

Figure 3.

Sustained inhibition of thalamic neuron produced by $120-\mathrm{Hz}$ stimulation of the GPi. (a) 100pulse stimulus train. (b) 1000-pulse stimulus train. From Anderson et al. 2003. 


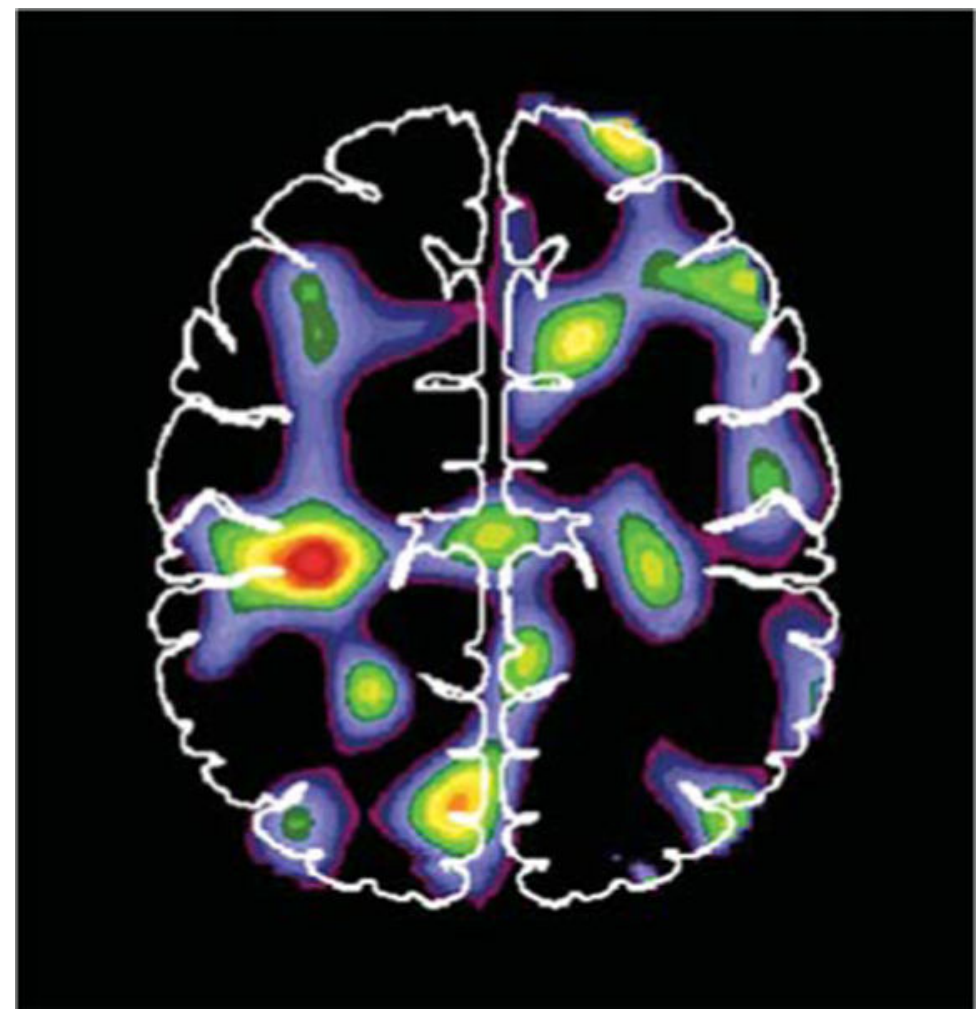

Figure 4.

Blood flow changes associated with the presence of tremor or other movement of the upper extremities during 1-min positron emission tomography (PET) scans in patients $(n=8)$ with subthalamic nucleus deep brain stimulation (STN DBS). These scans were collected with STN DBS off as part of a larger study of stimulation (Hershey et al. 2003). The image represents an averaged change in blood flow comparing paired scans for each patient with both STN stimulators off. During one scan there was no movement detected by videography or direct observation and no excessive activity seen on surface electromyography. During another scan there was movement or tremor. Arrows indicate peak blood flow increase of $5 \%$ in sensorimotor cortex. Such changes in motor behavior during PETs to investigate effects of DBS can confound the interpretation of findings. The scans collected during movement were excluded from our analysis of STN DBS effects (Hershey et al. 2003). 